\title{
Impact of crop field burning and mountains on heavy haze in the North China Plain: a case study
}

\author{
Xin Long ${ }^{1,2}$, Xuexi Tie ${ }^{1,3,4}$, Junji Cao ${ }^{1,5}$, Rujin Huang ${ }^{1,6}$, Tian Feng ${ }^{1}$, Nan Li ${ }^{1,7}$, Suyu Zhao ${ }^{1}$, Jie Tian ${ }^{1}$, Guohui Li ${ }^{1}$, \\ and Qiang Zhang ${ }^{8}$ \\ ${ }^{1}$ Key Lab of Aerosol Chemistry \& Physics, SKLLQG, Institute of Earth Environment, Chinese Academy of Sciences, \\ Xi'an 710061, China \\ ${ }^{2}$ University of Chinese Academy of Sciences, Beijing 100049, China \\ ${ }^{3}$ Center for Excellence in Urban Atmospheric Environment, Institute of Urban Environment, Chinese Academy of Sciences, \\ Xiamen 361021, China \\ ${ }^{4}$ National Center for Atmospheric Research, Boulder, CO, 80303, USA \\ ${ }^{5}$ Institute of Global Environmental Change, Xi' an Jiaotong University, Xi' an 710049, China \\ ${ }^{6}$ Laboratory of Atmospheric Chemistry, Paul Scherrer Institute (PSI), 5232 Villigen, Switzerland \\ ${ }^{7}$ Department of Atmospheric Science, National Taiwan University, Taipei 10617, Taiwan \\ ${ }^{8}$ Center for Earth System Science, Tsinghua University, Beijing 100084, China
}

Correspondence to: X. X. Tie (xxtie@urcar.edu) and R. J. Huang (rujin.huang@ieecas.cn)

Received: 26 January 2016 - Published in Atmos. Chem. Phys. Discuss.: 9 March 2016

Revised: 17 June 2016 - Accepted: 22 June 2016 - Published: 2 August 2016

\begin{abstract}
With the provincial statistical data and crop field burning (CFB) activities captured by Moderate Resolution Imaging Spectroradiometer (MODIS), we extracted a detailed CFB emission inventory in the North China Plain (NCP). The WRF-CHEM model was applied to investigate the impact of CFB on air pollution during the period from 6 to 12 October 2014, corresponding to a heavy haze incident with high concentrations of $\mathrm{PM}_{2.5}$ (particulate matter with aerodynamic diameter less than $2.5 \mu \mathrm{m}$ ). The WRF-CHEM model generally performed well in simulating the surface species concentrations of $\mathrm{PM}_{2.5}, \mathrm{O}_{3}$ and $\mathrm{NO}_{2}$ compared to the observations; in addition, it reasonably reproduced the observed temporal variations of wind speed, wind direction and planetary boundary layer height (PBLH). It was found that the CFB that occurred in southern NCP (SNCP) had a significant effect on $\mathrm{PM}_{2.5}$ concentrations locally, causing a maximum of $34 \% \mathrm{PM}_{2.5}$ increase. Under continuous southerly wind conditions, the CFB pollution plume went through a long-range transport to northern NCP (NNCP; with several mega cities, including Beijing, the capital city of China), where few CFBs occurred, resulting in a maximum of $32 \% \mathrm{PM}_{2.5}$ increase. As a result, the heavy haze in Beijing was enhanced by the CFB, which occurred in SNCP. Moun-
\end{abstract}

tains also play significant roles in enhancing the $\mathrm{PM}_{2.5}$ pollution in NNCP through the blocking effect. The mountains blocked and redirected the airflows, causing the pollutant accumulations along the foothills of mountains. This study suggests that the prohibition of CFB should be strict not only in or around Beijing, but also on the ulterior crop growth areas of SNCP. PM $_{2.5}$ emissions in SNCP should be significantly limited in order to reduce the occurrences of heavy haze events in the NNCP region.

\section{Introduction}

Crop residue burning is important for global biomass burning (Yevich and Logan, 2003; Shon, 2015), especially in agricultural countries such as China. Crop residue resources in China rank first in the world, accounting for $17.3 \%$ of the global production (Bi et al., 2010), and increasing with the average annual proportion of $4 \%$ (Hong et al., 2015; Zhao et al., 2010). Compared with other approaches, crop field burning (CFB) is the most effective and least expensive way to remove residues. The national annual average proportion of CFB to total residues is about $11-25 \%$ (Cao et al., 2008; Hao 
and Liu, 1994; Streets et al., 2003; Wang and Zhang, 2008; Zhao et al., 2010). Large numbers of annual CFB occur in China (Zhang et al., 2015; Yan et al., 2006), especially during the post-harvest seasons (Zhang et al., 2016; Shi et al., 2014; Cao et al., 2008). In addition, most of the CFB occurs on crop growth areas, such as the North China Plain (NCP) (Huang et al., 2012; Li et al., 2008), which have frequently suffered haze events in recent years (Yang et al., 2015; Jiang et al., 2015; Wang et al., 2014; Wang et al., 2012).

However, CFB has adverse impacts on traffic conditions and ecology environments (Shi et al., 2014; Zhang, 2009), and release plenty of pollutants, such as $\mathrm{CO}, \mathrm{SO}_{2}, \mathrm{VOC}$ (volatile organic compounds), $\mathrm{NO}_{x}$ and $\mathrm{PM}_{2.5}$ (particulate matter with aerodynamic diameter less than $2.5 \mu \mathrm{m}$ ) (Koppmann et al., 2005; Li et al., 2008). According to Guan et al. (2014) and Lu et al. (2011), annual CFB contributes about $13 \%$ of the total particulate matter (PM) emissions in China (Zhang et al., 2016). Furthermore, it is more prominent during the harvest periods due to its strong seasonal dependence. Numerous studies have quantified the contribution of biomass burning and CFB to PM pollution in China. According to Yao et al. (2016), Cheng et al. (2013), Wang et al. (2009, 2007) and Song et al. (2007), biomass burning has important impacts on the ambient $\mathrm{PM}_{2.5}$ concentrations (15-24\% in Beijing and 4-19\% in Guangzhou). Yang et al. (2010) captured a heavy pollution with $\mathrm{PM}_{10}$ concentrations higher than $350 \mu \mathrm{g} \mathrm{m}^{-3}$ in some CFB locations. It has been reported that CFB may contribute more than $30 \%$ of the $\mathrm{PM}_{10}$ increase during CFB incidents (Zhu et al., 2012; Zha et al., 2013; Su et al., 2012). Cheng et al. (2014) reported a summer case that CFB contributed $37 \%$ of $\mathrm{PM}_{2.5}$ concentrations in the Yangtze River delta.

The impact of CFB to air quality is continental and regional. Air quality in China is influenced by the CFB that occurs in Southeast Asia and on the Indian Peninsula (Qin et al., 2006). Mukai et al. (2014) reported that CFB emissions in Southeast Asia contribute the carbonaceous aerosols in Beijing. Within China, the inter-province transported air pollutants emitted from CFB significantly affect regional PM levels and air quality (Cheng et al., 2014; Zhu et al., 2012). For Beijing, the smoke particles from CFB are expected to be one of the major components (Wang et al., 2014; Cheng et al., 2013), though the percentage of transported sources are seldom specified (Zhang et al., 2016). A recent study reported that CFB and regional transport illustrated two of the key processes of haze formation in October 2014, especially on 6 October, but without quantitative estimation in this work (Yang et al., 2015). Related quantification studies are of great importance for the control strategies of CFB in Beijing.

Yanshan and Taihang mountains surround the NCP in the north and west (Fig. 1c). Such topography affects air pollution though the planetary boundary layer (PBL) in complex ways (Miao et al., 2015; Sun et al., 2013; Liu et al., 2009). $\mathrm{Hu}$ et al. (2014) reported that the Loess Plateau and NCP result in a mountain-plains solenoid circulation, exacerbat-
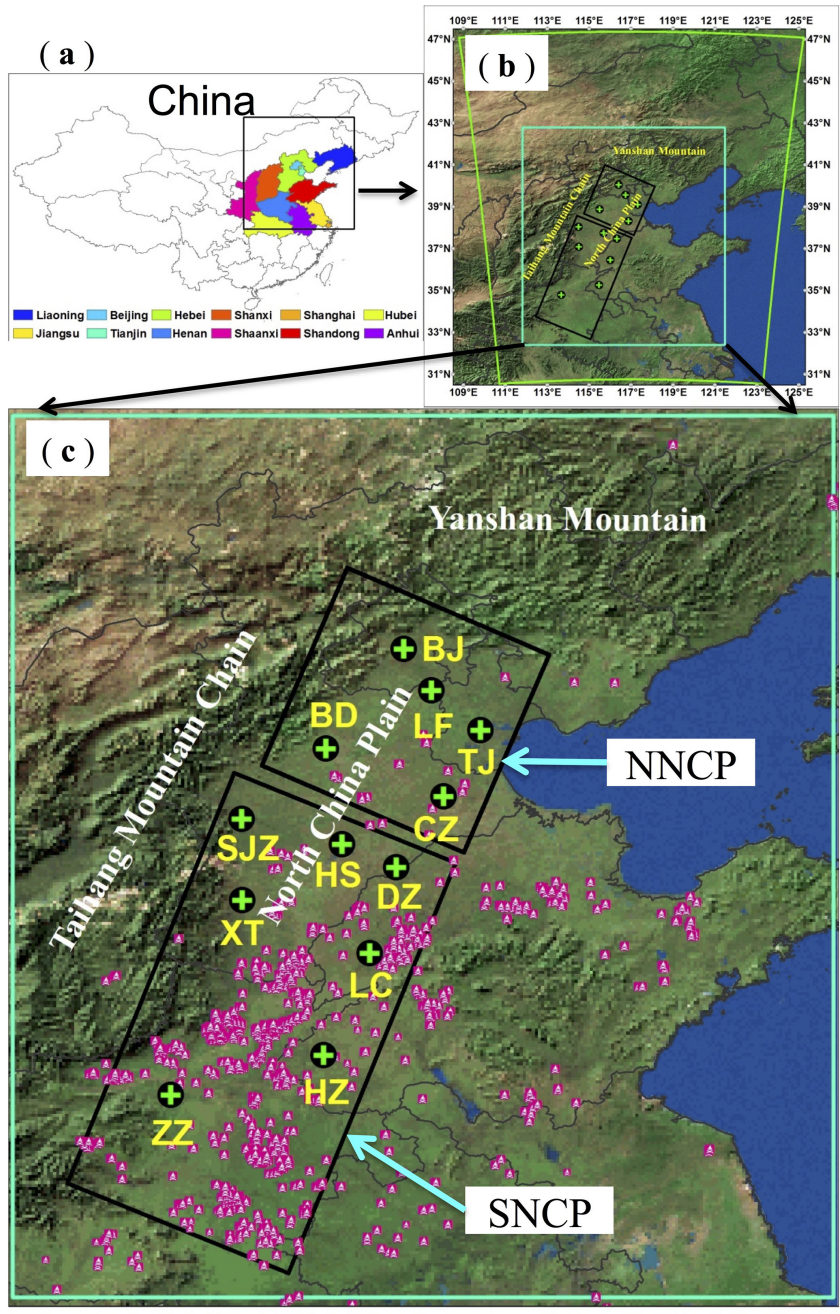

$\oplus$ Sampling sites $\quad$ Crop field burning

Provincial boundaries

Figure 1. The study area, sampling sites and crop fires. (a) The research domain and related provinces in China. (b) Topographical conditions of North China Plain. (c) Location of sampling sites and crop field burning captured by MODIS during the haze episode. Green crosses indicate the sampling sites, and the CFB are shown by the pink dots.

ing air pollution over NCP. Chen et al. (2009) found that a mountain chimney effect is dominated by mountain-valley breeze, enhancing the surface air pollution in Beijing. The mountain-plain breeze develops frequently in Beijing and may play important roles in modulating the local air quality (Miao et al., 2015; Hu et al., 2014; Chen et al., 2009). Miao et al. (2016) found that the mountains played a significant role in the sea-land aerosol circulation and the pollutants could be transported and accumulated in the NCP areas along the mountains, which is treated as the blocking effect (Zhao et al., 2015).

In this study, we analyzed a heavy haze episode that occurred in the NCP region from 12:00 to 00:00 local time (LT) on 6 to 12 October in 2014. During the period, the 
average $\mathrm{PM}_{2.5}$ concentrations are much higher than class II standard in both the southern NCP (SNCP) and northern $\mathrm{NCP}$ (NNCP). The characteristics of the air pollution were analyzed based on $\mathrm{PM}_{2.5}$ concentration. Depending on the satellite-based observations of Moderate Resolution Imaging Spectroradiometer (MODIS), a large number of CFB occurred in SNCP, whereas few CFBs occurred in NNCP. A more detailed CFB emission inventory was extracted. Thereafter we analyzed the regional transport of CFB emissions from the SNCP to NNCP driven by prevailing southerly winds. Under continuous southerly wind conditions, the mountains played an important role in northward transport, and caused an accumulation of the aerosol pollutants at the foothills of the mountains. We also analyzed the impact of mountains (especially the Taihang Mountains and the Yanshan Mountains) on the air pollution transport.

\section{Description of data}

\subsection{Geographical location}

In order to study the effect of CFB on local and regional air pollution, the research domain is located in eastern China, covering a large regional area (more than 10 provinces) (Fig. 1a). The NCP region is in the middle of the research domain, with two mountains in the north and west. The Yanshan Mountains are located in the north of NCP with eastwest directions, and the Taihang Mountains are located in the west of NCP with southwest-northeast directions (Fig. 1b). Figure 1c displays the distribution of online sampling sites and CFB captured by MODIS during the haze episode. We defined two regions of interests according to CFB occurrences, topographic conditions, industrial and agricultural developments. One is the northern NCP (NNCP), including two mega cities (Beijing and Tianjin) and the northern part of Hebei province, where few CFBs occurs. Another is the SNCP, where substantial CFB occurred during the haze episode as shown in Fig. 1c. Because of the severe haze problem in the capital city of China (Beijing), one of the main focuses is to study the long-range transport of CFB pollution from SNCP to NNCP.

\subsection{Meteorological conditions}

The reanalysis meteorological data, including wind direction, wind speed and planetary boundary layer height (PBLH) were obtained from the European Centre for Medium-range Weather Forecasts (ECMWF), with a spatial resolution of $0.125^{\circ} \times 0.125^{\circ}$. The data are available at http://www.ecmwf.int/products/data/. The average wind direction and wind speed are displayed in Table 1. During the haze episode, the mean wind directions are $174.8^{\circ}$ in NNCP and $165.2^{\circ}$ in SNCP, and the average wind speeds are $2.4 \mathrm{~m} \mathrm{~s}^{-1}$ in both NNCP and SNCP. The results suggest that the prevailing winds are continuous southerly winds with weak wind speeds, which are favorable to long-range transport of pollution from SNCP to NNCP, which has been reported as one of the major contributors to haze formation in the Beijing City (Tie et al., 2015).

\section{$2.3 \quad \mathbf{P M}_{2.5}$ measurements}

The hourly $\mathrm{PM}_{2.5}$ mass concentrations were continuously monitored by the Ministry of Environmental Protection (MEP) of China (http://datacenter.mep.gov.cn), including five sites in NNCP and seven sites in SNCP (indicated by green crosses in Fig. 1c). The data were updated from the website: http://www.pm25.in/. Table 1 summarizes the site information and the observed $\mathrm{PM}_{2.5}$ concentrations. During the study period, the average $\mathrm{PM}_{2.5}$ concentrations are $200.0 \mu \mathrm{g} \mathrm{m}^{-3}$ in NNCP and $184.1 \mu \mathrm{g} \mathrm{m}^{-3}$ in SNCP. The measured $\mathrm{PM}_{2.5}$ concentrations are much higher than a class II standard (daily mean of $75 \mu \mathrm{g} \mathrm{m}^{-3}$ ), indicating an occurrence of a heavy pollution event. We analyzed the characteristics of the air pollution based on the $\mathrm{PM}_{2.5}$ concentration simulated by WRF-CHEM. Meanwhile, it is worth noting that the highest $\mathrm{PM}_{2.5}$ concentrations occurred along the foothill sites of the Taihang Mountains. At the foothill sites of Beijing, Baoding, Shijiazhuang and Xingtai, $\mathrm{PM}_{2.5}$ concentrations are $245.5,287.7,257.9$ and $320.1 \mu \mathrm{g} \mathrm{m}^{-3}$, respectively. The mean $\mathrm{PM}_{2.5}$ concentration in these four sites is $277.8 \mu \mathrm{g} \mathrm{m}^{-3}$, much higher than $147.2 \mu \mathrm{g} \mathrm{m}^{-3}$ averaged from the other sites. Considering the continuous southerly winds and the topographic conditions, we studied the impact of the mountains on the air pollution transport.

\section{Methods}

\subsection{Model description}

We used Weather Research and Forecasting Chemical model (WRF-CHEM) (Grell et al., 2005) to simulate the spatial and temporal variability of $\mathrm{PM}_{2.5}$ concentration. The specific version of the WRF-CHEM model is developed by $\mathrm{Li}$ et al. $(2010,2011,2012)$, with a new flexible gas-phase chemical module and the CMAQ (Community Multi-scale Air Quality) (version 4.6) aerosol module developed by US EPA (Binkowski and Roselle, 2003). The wet deposition follows the CMAQ method and the dry deposition is parameterized following Wesely (1989). The photolysis rates are calculated using the FTUV (Fast Radiation Transfer Model) (Li et al., 2005; Tie et al., 2003), in which the impacts of aerosols and clouds on the photochemistry are considered (Li et al., 2011). The gas-phase chemistry was represented in the model by the modified RADM2 (Regional Acid Deposition Model, version 2) gas-phase chemical mechanism (Stockwell et al., 1990; Chang et al., 1987). Meanwhile, the ISORROPIA version 1.7 (http://nenes.eas.gatech.edu/ISORROPIA/) is utilized to simulate the inorganic aerosols, which is primarily used to predict the thermodynamic equilibrium between the 
Table 1. The average $\mathrm{PM}_{2.5}$ concentration, wind direction and wind speed of the observations from 12:00 to 00:00 LT on 6 to 12 Oct. The sampling sites located at the foot of mountains are emphasized in bold.

\begin{tabular}{llrrrrr}
\hline Region & Site & $\begin{array}{r}\text { Longitude } \\
\left({ }^{\circ} \mathrm{E}\right)\end{array}$ & $\begin{array}{r}\text { Latitude } \\
\left({ }^{\circ} \mathrm{N}\right)\end{array}$ & $\begin{array}{r}\mathrm{PM}_{2.5} \\
\left(\mu \mathrm{g} \mathrm{m}^{-3}\right)\end{array}$ & $\begin{array}{r}\text { Wind dir. } \\
\left({ }^{\circ}\right)\end{array}$ & $\begin{array}{r}\text { Wind spd. } \\
\left(\mathrm{m} \mathrm{s}^{-1}\right)\end{array}$ \\
\hline NNCP & Beijing (BJ) & 116.41 & 40.04 & $\mathbf{2 4 5 . 5}$ & 185.8 & 2.2 \\
& Langfang (LF) & 116.73 & 39.56 & 214.7 & 177.0 & 2.4 \\
& Tianjin (TJ) & 117.31 & 39.09 & 134.7 & 173.5 & 2.4 \\
& Baoding (BD) & 115.49 & 38.87 & $\mathbf{2 8 7 . 7}$ & 171.2 & 2.2 \\
& Cangzhou (CZ) & 116.87 & 38.31 & 117.3 & 166.6 & 2.5 \\
& & & $\mathbf{2 0 0 . 0}$ & $\mathbf{1 7 4 . 8}$ & $\mathbf{2 . 3 5}$ \\
\hline SNCP & Shijiazhuang (SJZ) & 114.49 & 38.04 & $\mathbf{2 5 7 . 9}$ & 175.2 & 2.0 \\
& Hengshui (HS) & 115.68 & 37.74 & 166.7 & 163.7 & 2.6 \\
& Dezhou (DZ) & 116.31 & 37.47 & 152.4 & 162.7 & 2.6 \\
& Xingtai (XT) & 114.50 & 37.09 & $\mathbf{3 2 0 . 1}$ & 198.1 & 2.3 \\
& Liaocheng (LC) & 116.00 & 36.46 & 139.7 & 158.4 & 2.6 \\
& Hezhe (HZ) & 115.46 & 35.26 & 105.0 & 138.9 & 2.4 \\
& Zhengzhou (ZZ) & 113.66 & 34.79 & 146.9 & 159.2 & 2.4 \\
& & & $\mathbf{1 8 4 . 1}$ & $\mathbf{1 6 5 . 2}$ & $\mathbf{2 . 4 2}$ \\
\hline
\end{tabular}

ammonia-sulfate-nitrate-chloride-water aerosols and their gas-phase precursors of $\mathrm{H}_{2} \mathrm{SO}_{4}-\mathrm{HNO}_{3}-\mathrm{NH}_{3}-\mathrm{HCl}$-water vapor. The Yonsei University (YSU) PBL scheme (Hong et al., 2006), Lin microphysics scheme (Lin et al., 1983) and Noah land-surface model (Chen and Dudhia, 2001) were utilized. The model has been successfully applied in several regional pollution studies (Tie et al., 2009, 2007; He et al., 2015).

The WRF-CHEM model is configured with resolution of $6 \mathrm{~km} \times 6 \mathrm{~km}(200 \times 300$ grid cells $)$ centered in $\left(117^{\circ} \mathrm{E}\right.$, $39^{\circ} \mathrm{N}$ ). Vertical layers extend from the surface to $50 \mathrm{hPa}$, with 28 vertical layers, involving seven layers in the bottom of $1 \mathrm{~km}$. The meteorological initial and boundary conditions were gathered from NCEP FNL (National Centers for Environmental Prediction Final) Operational Global Analysis data. The lateral chemical initial conditions were constrained by a global chemical transport model - MOZART4 (Model for Ozone and Related chemical Tracers, version 4) $-6 \mathrm{~h}$ output (Emmons et al., 2010; Tie et al., 2005). For the episode simulations, the spin-up time of the WRF-CHEM model is 3 days.

The surface emission inventory used in this study was obtained from the Multi-resolution Emission Inventory for China (MEIC) (Zhang et al., 2009), which is an update and improvement for the year 2010 (http://www.meicmodel.org). The emission inventory estimated only anthropogenic emission such as non-residential sources (transportation, agriculture, industry and power) and residential sources related to fuel combustions. The biogenic emissions are calculated online with the WRF-CHEM model using the MEGAN model (Guenther et al., 2006). Additionally, we added emission from CFB in the present study.

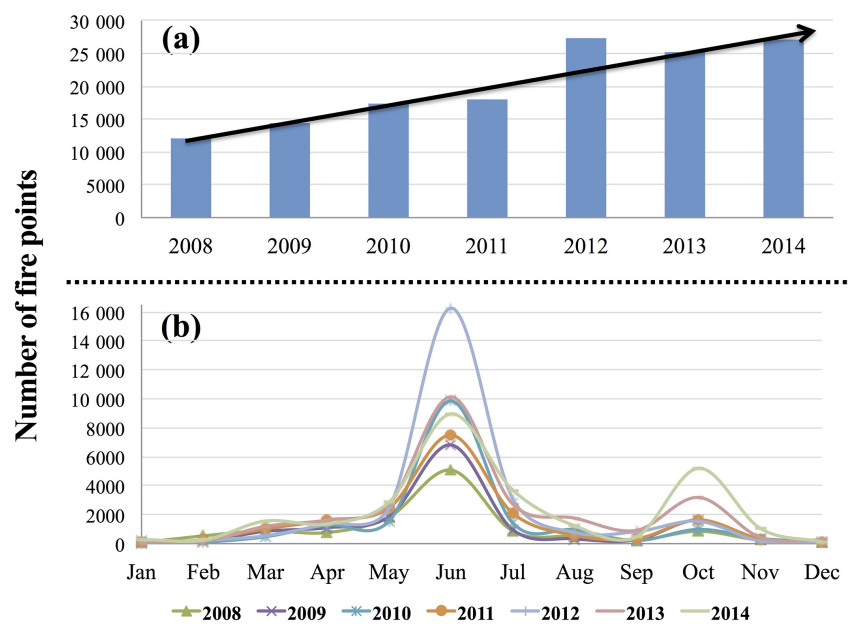

Figure 2. The (a) yearly and (b) monthly CFB observed by MODIS in the research domain during the year of 2008 to 2014.

\subsection{Crop field burning emissions}

We analyzed the annual and monthly number of open crop fire events captured by MODIS in the research domain from 2008 to 2014. In the NCP region, the CFB activities gradually increase from the minimum fire events of 12000 times in 2008 to 27000 times in 2014 (Fig. 2a), suggesting that the CFB is not efficiently controlled in this region. This situation may result from the limitation of local enforcement of regulation despite the fact that CFB has already been banned (Zhang and Cao, 2015; Shi et al., 2014). The CFB have a seasonal pattern due to the post-harvest activities with two distinct peaks in summer and autumn, especially in June (33$59 \%)$ and October (6-19\%) (Fig. 2b). The strong seasonal 
dependence character suggests that the CFB emissions during October are much larger than annual averages. In order to have the detailed horizontal distribution of the pollutant emissions of $\mathrm{CFB}$, we elaborated a method to generate emission inventory using the satellite data of "MODIS Thermal Anomalies/Fire product (MOD/MYD14DL)". The MOD/MYD14DL product can detect small opening fires $\left(<100 \mathrm{~m}^{2}\right)$ (Giglio et al., 2003) and produce the geographic location of open fire activities (van der Werf et al., 2006). In this study, the CFB was defined as MOD/MYD14DL active fires occurred over the cropland, which is classified by the MODIS Combined Land Cover Type product (Friedl et al., 2010).

First, we estimated the $\mathrm{CO}$ emission of $\mathrm{CFB}$, utilizing a widely used method (Streets et al., 2003; Cao et al., 2008; Zhang et al., 2008; Ni et al., 2015) based on the annual provincial statistical data. The provincial emission of crop residues burning can be calculated by Eq. (1):

$E_{i, \mathrm{CO}}=\sum_{k=1}^{3} P_{i, k} \times F_{i} \times D_{k} \times R_{k} \times \mathrm{CE}_{k} \times \mathrm{EF}_{\mathrm{CO}}$

where $i$ stands for each province and $k$ for different crop species of rice, corn and wheat. $E_{i, \mathrm{CO}}$ stands for $\mathrm{CO}$ emission from CFB of $i$ th province in gigagrams $[\mathrm{Gg}] . P_{i, k}$ is the yield of crop in Gg. $F_{i}$ is the proportion of residues burned in the field. $D_{k}$ is the dry fraction of crop residue (dry matter). $R_{k}$ is the residue-to-crop ratio (dry matter). $\mathrm{CE}_{k}$ is the combustion efficiency and $\mathrm{EF}_{\mathrm{CO}}$ is the emission factors of $\mathrm{CFB}$. The $P_{i, k}$ values were taken from an official statistical yearbook (NBS, 2015) (Table S1 in the Supplement), and the $F_{i}$ on a provincial basis were taken from Wang and Zhang (2008) and Zhang Yisheng (Unpublished doctor thesis-in Chinese) (Table S1). The parameters of $D_{k}, R_{k}$ and $\mathrm{CE}_{k}$ are listed in Table $\mathrm{S} 2$. The $\mathrm{EF}_{\mathrm{CO}}$ from $\mathrm{CFB}$ was summarized range from 52 to $141 \mathrm{~g} \mathrm{~kg}^{-1}$ in China (Table S3). In this study, we used $111 \mathrm{~g} \mathrm{~kg}^{-1}$ as the average $\mathrm{EF}_{\mathrm{CO}}$ of crop residue, which was used to estimate the emissions from global open burning (Wiedinmyer et al., 2011).

The provincial $\mathrm{CO}$ emission was temporally and spatially allocated according to the CFB activities. The detailed daily $\mathrm{CO}$ emission of $k$ th grid $\left(E_{k, \mathrm{CO}}\right)$ was calculated using Eq. (2):

$E_{k, \mathrm{CO}}=\frac{\mathrm{FC}_{k}}{\mathrm{FC}_{i}} \times E_{i, \mathrm{CO}}$,

where $\mathrm{FC}_{k}$ and $\mathrm{FC}_{i}$ are the total CFB fire counts in $k$ th grid and $i$ th province, respectively (Table $\mathrm{S} 1$ ).

Thereafter, the emissions of various gaseous and particulate species $\left(E_{\mathrm{spec} 1}\right)$ were calculated by the Eq. (3). Furthermore, individual chemical compounds $\left(E_{\text {spec2 }}\right)$ were calculated by Eq. (4):
$E_{k, \text { spec } 1}=\frac{\mathrm{EF}_{\mathrm{spec} 1}}{\mathrm{EF}_{\mathrm{CO}}} \times E_{k, \mathrm{CO}}$,

$E_{k, \text { spec } 2}=E_{k, \mathrm{NMOC}} \times$ scale,

where $E_{k \text {,spec1 }}$ and $E_{k \text {,spec2 }}$ are the $k$ th grid emission of the specify WRF-CHEM species, $E_{\text {spec1 }}$ and $E_{C O}$ are the emission factors of CFB, $E_{k, \mathrm{NMOC}}$ is NMOC emission in the $k$ th grid calculated by Eq. (3) and scale is the value to convert NMOC emissions to WRF-CHEM chemical species. The emission factors for gaseous and particulate species and scale to convert NMOC emissions to WRF-CHEM chemical species from CFB were taken from available data sets (Wiedinmyer et al., 2011; Akagi et al., 2011; Andreae and Merlet, 2001), which were summarized by Wiedinmyer et al. (2011) (Table 2).

\section{Results and discussions}

\subsection{Evaluate the crop field burning emission}

The provincial $\mathrm{CO}$ emissions of $\mathrm{CFB}$ were estimated based on Eq. (1), and there was 8.2 Tg CO emitted from CFB in 2014 (Table S1). This result is comparable to previous studies, which were 4.6-10.1 $\mathrm{Tg} \mathrm{yr}^{-1}$ (Cao et al., 2008; Ni et al., 2015; Streets et al., 2003; Yan et al., 2006). According to the MODIS observations, a large number of CFB occurred in SNCP, including the provinces of Henan with $61 \%$ and Shandong with $22 \%$. Most of CFB occurred on 6 and 7 October, accounting for $75 \%$ (Table 3).

Table 4 shows the CFB emissions of gaseous and particulate species on 6 and 7 October, including the mega cities of Beijing and Tianjin, and provinces of Hebei, Henan and Shandong in NCP. Figure 3 displays the CFB activities and related $\mathrm{CO}$ emission on 6 and 7 October. Most of the pollutants are emitted from Henan in SNCP, accounting for $73 \%$ on 6 October and $65 \%$ on 7 October. Plenty of pollutants emitted from $\mathrm{CFB}$ on 6 October, producing more than $5.1 \mathrm{Gg}$ $\mathrm{PM}_{2.5}$ and 98.0 Gg CO $\left(1 \mathrm{Gg}=10^{9} \mathrm{~g}\right)$.

\subsection{Statistical characteristics of the evaluation}

The characteristics of the haze pollution were defined by $\mathrm{PM}_{2.5}$ concentration, which is significantly affected by the local wind fields and PBLH in the NCP region (Tie et al., 2015). In order to evaluate the model performance, the model simulations were compared with the measured results in both species concentrations $\left(\mathrm{PM}_{2.5}, \mathrm{O}_{3}\right.$ and $\left.\mathrm{NO}_{2}\right)$ and meteorological parameters (wind speed, wind direction and PBLH). The normalized mean bias (NMB) and correlation coefficient $(R)$ were used to quantify the performance. 
Table 2. The gaseous and particulate species emission factors $\left(\mathrm{g} \mathrm{kg}^{-1}\right)$ and scales to convert NMOC emissions (kg day $\left.{ }^{-1}\right)$ to WRF-CHEM chemical species (moles-species day ${ }^{-1}$ ) from crop field burning. The detailed chemical species are described by Stockwell et al. (1990).

\begin{tabular}{|c|c|c|c|c|c|c|c|c|c|c|c|c|}
\hline \multicolumn{7}{|c|}{ Gaseous species } & \multicolumn{6}{|c|}{ Particulate species } \\
\hline $\mathrm{CO}^{\mathrm{a}}$ & $\mathrm{NO}_{x}^{\mathrm{a}}$ & $\mathrm{NO}^{\mathrm{a}}$ & $\mathrm{NO}_{2}^{\mathrm{b}}$ & $\mathrm{SO}_{2}^{\mathrm{c}}$ & $\mathrm{NH}_{3}^{\mathrm{a}}$ & $\mathrm{NMOC}^{\mathrm{a}}$ & $\mathrm{OC}^{\mathrm{c}}$ & $\mathrm{BC}^{\mathrm{c}}$ & $\mathrm{PM}_{2.5} \mathrm{a}$ & & & \\
\hline 111 & 3.5 & 1.7 & 3.9 & 0.4 & 2.3 & 57 & 3.3 & 0.69 & 5.8 & & & \\
\hline \multicolumn{13}{|c|}{ Chemical-compounds-to-NMOC scales ${ }^{\mathrm{a}, \mathrm{b}}$} \\
\hline ETH & $\mathrm{HC} 3$ & HC5 & OL2 & OLT & OLI & TOL & CSL & $\mathrm{HCHO}$ & ALD & KET & ORA2 & ISO \\
\hline 0.43 & 0.73 & 0.07 & 1.09 & 0.27 & 0.20 & 1.07 & 0.49 & 1.84 & 3.05 & 0.83 & 2.19 & 0.60 \\
\hline
\end{tabular}

${ }^{a}$ The values were taken from Andreae and Merlet (2001). ${ }^{b}$ The values were taken from Wiedinmyer et al. (2011). ${ }^{c}$ The values were taken from Akagi et al. (2011).

Table 3. The fire counts of crop field burning detected by the MODIS in the provinces over NCP during the haze episode (from 6 to 11 October 2014).

\begin{tabular}{lrrrrrrr}
\hline Province & 6 Oct & 7 Oct & 8 Oct & 9 Oct & 10 Oct & 11 Oct & Percentage \\
\hline Beijing & 0 & 0 & 0 & 0 & 0 & 0 & $0 \%$ \\
Tianjin & 0 & 0 & 0 & 0 & 0 & 0 & $0 \%$ \\
Hebei & 60 & 11 & 14 & 1 & 5 & 6 & $10 \%$ \\
Henan & $\mathbf{3 7 0}$ & $\mathbf{1 0 4}$ & 59 & 18 & 19 & 23 & $\mathbf{6 1} \%$ \\
Shandong & $\mathbf{1 0 0}$ & $\mathbf{5 4}$ & 9 & 9 & 32 & 7 & $\mathbf{2 2} \%$ \\
Anhui & 6 & 6 & 20 & 0 & 10 & 3 & $5 \%$ \\
Shanxi & 3 & 0 & 0 & 3 & 4 & 1 & $1 \%$ \\
Jiangsu & 4 & 3 & 5 & 0 & 3 & 1 & $2 \%$ \\
Percentage & $\mathbf{5 6 \%}$ & $\mathbf{1 8} \%$ & $11 \%$ & $3 \%$ & $8 \%$ & $4 \%$ & $100 \%$ \\
\hline
\end{tabular}

$\mathrm{NMB}=\frac{\sum_{i=1}^{N}\left(P_{i}-O_{i}\right)}{\sum_{i=1}^{N} O_{i}}$,
$R=\frac{\sum_{i=1}^{N}\left(P_{i}-\bar{P}\right)\left(O_{i}-\bar{O}\right)}{\left[\sum_{i=1}^{N}\left(P_{i}-\bar{P}\right)^{2} \sum_{i=1}^{N}\left(O_{i}-\bar{O}\right)^{2}\right]^{\frac{1}{2}}}$,

where $P_{i}$ is the predicted results and $O_{i}$ represents the related observations. $\mathrm{N}$ is the total number of the predictions used for comparisons. Meanwhile, $\bar{P}$ and $\bar{O}$ are the average prediction and related mean observation, respectively.

Figure 4 shows the measured and calculated temporal variations of regional average species concentrations, including $\mathrm{PM}_{2.5}, \mathrm{O}_{3}$ and $\mathrm{NO}_{2}$. The WRF-CHEM model reproduced the pollution episode well, with a good agreement with observations. The $R$ of simulated and measured $\mathrm{PM}_{2.5}$ concentrations are 0.88 in both NNCP and SNCP (Fig. 4a). The simulations are overall lower than the observations with NMB of $-12 \%$ in NNCP and $-7 \%$ in SNCP. Considering the high average $\mathrm{PM}_{2.5}$ concentration with $200.0 \mu \mathrm{g} \mathrm{m}^{-3}$ in NNCP and $184.1 \mu \mathrm{g} \mathrm{m}^{-3}$ in SNCP, obvious underestimates exist with the overall concentrations of $24.0 \mu \mathrm{g} \mathrm{m} \mathrm{m}^{-3}$ in NNCP and $12.9 \mu \mathrm{g} \mathrm{m}^{-3}$ in SNPC. This may be related to the CMAQ (version 4.6) aerosol module, which is likely to underestimated OM (Organic Matter) due to the uncertainty in secondary organic aerosols mechanism (Baek et al., 2011). Meanwhile, the underestimates are also related to the negative bias in S3, which may be related to cloud contamination (Fig. S1 in the Supplement). Whereas this has only a few impacts on the estimation of CFB contributions since few CFBs occurred during S3. The simulations of $\mathrm{O}_{3}$ and $\mathrm{NO}_{2}$ also agree well with observations, with $R$ greater than 0.77 and absolute NMB lower than $17 \%$ (Fig. $4 \mathrm{~b}$ and c). Figure 5 displays the measured and calculated temporal variations of regional average meteorological parameters, including wind speed, wind direction, and the PBLH. The comparisons between simulated and observed wind fields show good agreements in both NNCP and SNCP (Fig. 5a and b), with $R$ all higher than 0.64 , and the absolute NMB is no more than $15 \%$. Meanwhile, the $R$ of PBLH is larger than 0.88 and the absolute NMB is no more than $10 \%$ (Fig. 5c).

\subsection{Characteristics of the heavy pollution events}

According to the evolution of $\mathrm{PM}_{2.5}$ concentration (Fig. 4a), the haze episode can be divided into three stages: (i) pollution formation stage (S1, 12:00-00:00 LT on 6-8 Oct), (ii) pollution outbreak stage (S2, 00:00-00:00 LT on 8-10 Oct) and (iii) pollution clear stage (S3, 00:00-00:00 LT on 10-12 Oct). 
Table 4. The emissions $\left(\mathrm{Gg}_{\mathrm{day}}{ }^{-1}\right)$ of gaseous and particulate species from crop field burning on 6 and 7 October in NCP region, including the provinces of Beijing, Tianjin, Hebei, Henan and Shandong.

\begin{tabular}{llrrrrrrrrrr}
\hline Time & Province & $\mathrm{CO}$ & $\mathrm{NO}_{x}$ & $\mathrm{NO}$ & $\mathrm{NO} 2$ & $\mathrm{NMOC}^{2}$ & $\mathrm{SO}_{2}$ & $\mathrm{NH}_{3}$ & $\mathrm{PM}_{2.5}$ & $\mathrm{OC}$ & $\mathrm{BC}$ \\
\hline \multirow{2}{*}{ 6 Oct } & Beijing & 0.00 & 0.00 & 0.00 & 0.00 & 0.00 & 0.00 & 0.00 & 0.00 & 0.00 & 0.00 \\
& Tianjin & 0.00 & 0.00 & 0.00 & 0.00 & 0.00 & 0.00 & 0.00 & 0.00 & 0.00 & 0.00 \\
& Hebei & 10.58 & 0.33 & 0.16 & 0.37 & 5.44 & 0.04 & 0.22 & 0.55 & 0.31 & 0.07 \\
& Henan & 71.17 & 2.24 & 1.09 & 2.50 & 36.55 & 0.26 & 1.47 & 3.72 & 2.12 & 0.44 \\
& Shandong & 16.27 & 0.51 & 0.25 & 0.57 & 8.35 & 0.06 & 0.34 & 0.85 & 0.48 & 0.10 \\
\hline \multirow{2}{*}{ 7 Oct } & Total & 98.0 & 3.1 & 1.5 & 3.4 & 50.3 & 0.4 & 2.0 & 5.1 & 2.9 & 0.6 \\
& Beijing & 0.00 & 0.00 & 0.00 & 0.00 & 0.00 & 0.00 & 0.00 & 0.00 & 0.00 & 0.00 \\
& Tianjin & 0.00 & 0.00 & 0.00 & 0.00 & 0.00 & 0.00 & 0.00 & 0.00 & 0.00 & 0.00 \\
& Hebei & 1.94 & 0.06 & 0.03 & 0.07 & 1.00 & 0.01 & 0.04 & 0.10 & 0.06 & 0.01 \\
& Henan & 20.01 & 0.63 & 0.31 & 0.70 & 10.27 & 0.07 & 0.41 & 1.05 & 0.59 & 0.12 \\
& Shandong & 8.79 & 0.28 & 0.13 & 0.31 & 4.51 & 0.03 & 0.18 & 0.46 & 0.26 & 0.05 \\
\hline & Total & 30.7 & 1.0 & 0.5 & 1.1 & 15.8 & 0.1 & 0.6 & 1.6 & 0.9 & 0.2 \\
\hline
\end{tabular}

The major characteristics of each stage are briefly summarized below. Related simulations in bracket follow the detailed observations.

- S1 (pollution formation): it is dominated by a continuous southerly wind, with a mean wind speed of 2.5 (2.7) $\mathrm{m} \mathrm{s}^{-1}$ in NNCP and 3.0 (3.6) $\mathrm{m} \mathrm{s}^{-1}$ in SNCP. The backward trajectories, with the HYSPLIT model online version, of Beijing, Tianjin and Baoding during $\mathrm{S} 1$ reflected how the CFB influenced the NNCP region (Fig. 6). The air mass mainly came from the south, originating from the SNCP region. The pollutants are continuously transported from SNCP to NNCP, leading to pollutants accumulation in NNCP, which is characterized by the steady rising of $\mathrm{PM}_{2.5}$ concentration in $\mathrm{NNCP}$ from 20.6 (41.0) $\mathrm{\mu g} \mathrm{m}^{-3}$ (at 12:00, 6 October) to 242.7 (217.5) $\mu \mathrm{g} \mathrm{m}^{-3}$ (at 00:00 LT on 8 October) (Fig. 4 a1).

- S2 (pollution outbreak): during S2, the air pollution deteriorates. It is a relative stable period of heavy pollution with average $\mathrm{PM}_{2.5}$ concentration of 252.0 (241.2) $\mu \mathrm{g} \mathrm{m}^{-3}$ in NNCP and $214.1(235.0) \mu \mathrm{g} \mathrm{m} \mathrm{m}^{-3}$ in SNCP, which are higher than those in other stages. This phenomenon may be related to the relatively lower wind speed and PBLH.

- S3 (pollution clear): during S3, the southerly winds gradually decrease, and turn to northerly winds at the end of S3. Clean airs from the north region of China obviously improve the air quality. Compared with S2, the average $\mathrm{PM}_{2.5}$ concentrations are decreased in both NNCP and SNCP.

There were several important issues shown in the results, and should be addressed. (1) The $\mathrm{PM}_{2.5}$ concentrations are extremely high during the S2 period, and the daily average concentrations are greater than the Chinese National Standard $\left(75 \mu \mathrm{g} \mathrm{m}^{-3}\right)$ by $2-3$ times. (2) The air pollution is severe in a large region (occurred in both NNCP and SNCP). (3) During the $\mathrm{S} 1$ and $\mathrm{S} 2$ periods, there is a time lag between SNCP and NNCP for $\mathrm{PM}_{2.5}$ concentrations. Because it is a continuous southerly wind condition, it shows the important impact of long-range transport of $\mathrm{PM}_{2.5}$ particles from the SNCP to NNCP.

\subsection{Contributions of crop field burning}

Model sensitivity studies were conducted to separate the individual CFB contribution. Two model simulations were performed, i.e., one with both anthropogenic and CFB emissions while the other with only anthropogenic emission. We calculated $\mathrm{PM}_{2.5}$ distributions by including CFB emissions (anthropologic and $\mathrm{CFB}$ ) and excluding CFB emissions (only anthropologic). In this study, the CFB contributions were quantified by regional average contribution in mass concentration $\left(\mathrm{CPM}_{2.5}\right)$ and daily average contribution proportion $\left(\overline{\mathrm{PPM}_{2.5}}\right)$ :

$$
\begin{aligned}
& \mathrm{CPM}_{2.5}=\frac{\mathrm{TPM}_{2.5}-\mathrm{APM}_{2.5},}{\overline{\mathrm{PPM}_{2.5}}=\frac{\overline{\mathrm{CPM}_{2.5}}}{\overline{\mathrm{TPM}_{2.5}}},}
\end{aligned}
$$

where $\mathrm{TPM}_{2.5}$ represents the simulated $\mathrm{PM}_{2.5}$ concentrations considering total emission; $\mathrm{APM}_{2.5}$ denotes the simulated $\mathrm{PM}_{2.5}$ concentrations only considering anthropologic emissions. $\overline{\mathrm{CPM}}_{2.5}$ and $\overline{\mathrm{TPM}_{2.5}}$ are daily average value for $\mathrm{CPM}_{2.5}$ and $\mathrm{TPM}_{2.5}$, respectively.

Figure 7 displays the regional observed and simulated $\mathrm{PM}_{2.5}$ concentrations considering total emissions (anthropologic and CFB) and only anthropologic emissions. It is clearly shown that the CFB had important contributions to $\mathrm{PM}_{2.5}$ in both NNCP (Fig. 7a) and SNCP (Fig. 7b). This is 

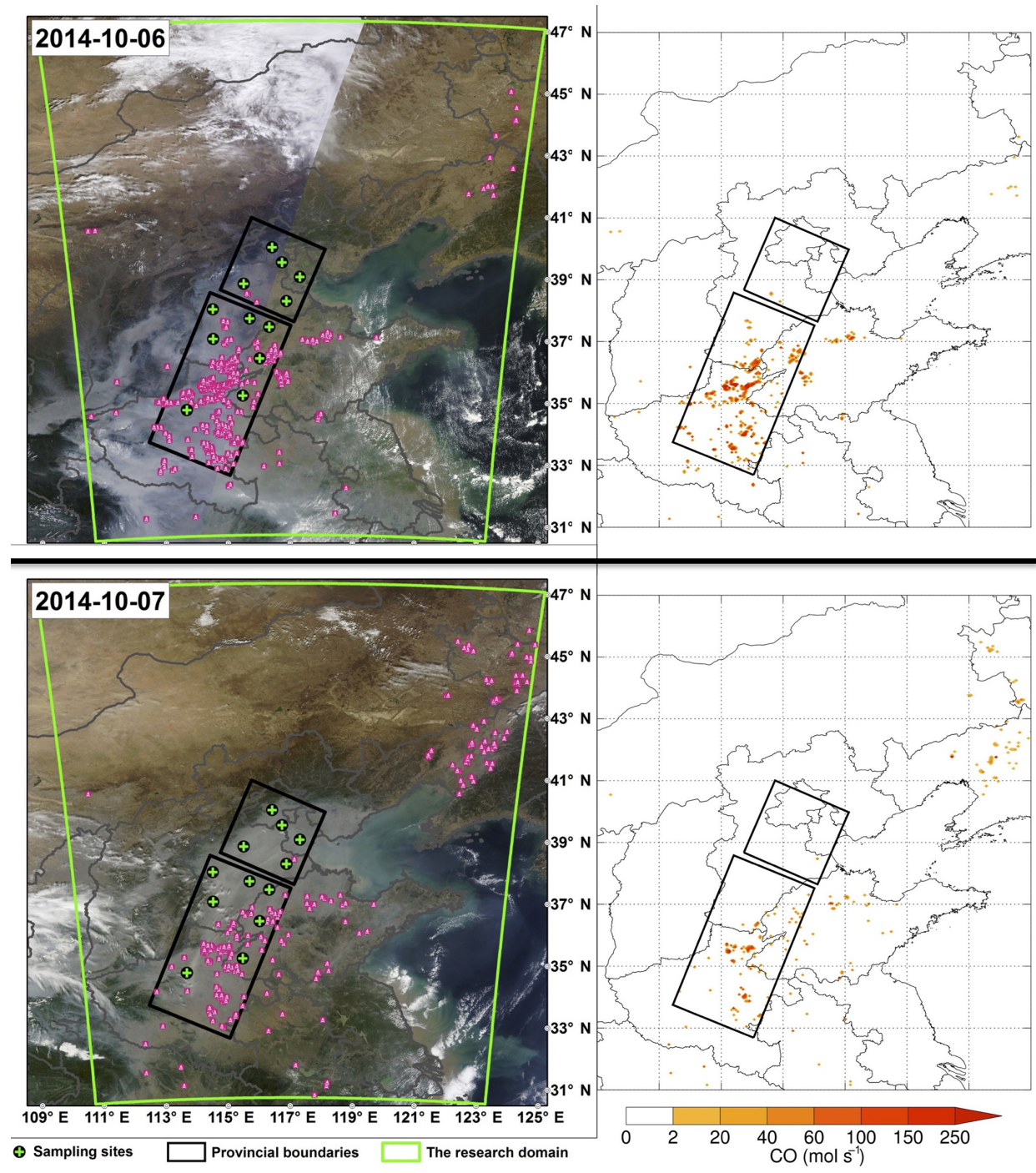

Figure 3. CFB captured by MODIS with the background of MODIS real-time true color map (left) and related CO emission (right) on 6 and 7 October.

Table 5. Average contribution proportion of crop field burning to $\mathrm{PM}_{2.5}$ concentration.

\begin{tabular}{lrrrrrr}
\hline Region & 6 Oct & 7 Oct & 8 Oct & 9 Oct & 10 Oct & 11 Oct \\
\hline NNCP & $5 \%$ & $\mathbf{3 2} \%$ & $\mathbf{1 0} \%$ & $3 \%$ & $2 \%$ & $4 \%$ \\
SNCP & $\mathbf{3 4} \%$ & $\mathbf{1 7} \%$ & $6 \%$ & $3 \%$ & $1 \%$ & $1 \%$ \\
\hline
\end{tabular}

also proved by the daily $\overline{\mathrm{PPM}_{2.5}}$ of CFB (Table 5). The high values of $\overline{\mathrm{PPM}_{2.5}}$ in SNCP appear on 6 October with $34 \%$ and on 7 October with $17 \%$, when plenty of CFB occurred. Simultaneously, the high values of $\overline{\mathrm{PPM}}_{2.5}$ in NNCP appear on 7 October with $32 \%$ and 8 October with $10 \%$, showing a later occurrence than that in SNCP. The time lag suggests that the plume with CFB may be transported from SNCP to NNCP.
The detailed hourly CFB contributions to $\mathrm{PM}_{2.5}$ concentrations $\left(\mathrm{CPM}_{2.5}\right)$ are displayed in Fig. 8. The values of $\mathrm{CPM}_{2.5}$ in NNCP are generally lag synchronized with that in SNCP, such as $P_{N 1}$ versus $P_{S 1}$ and $P_{N 2}$ versus to $P_{S 2}$ (Fig. 8a and b). Apparently, the lagged time is not constant and varied with the wind fields. The specific details perform relaxed lag synchronized, especially between the $P_{N 2}$ and $P_{S 2}$. This phenomenon further indicates that the CFB contribution in SNCP is mainly due to local emission, whereas the CFB contribution in NNCP is largely a result of long-range transport from SNCP. Indeed, the CFB pollution plume goes through a long-range transport to NNCP can cause an obvious increase to $\mathrm{PM}_{2.5}$ concentration, with the maximum daily average contribution of $32 \%$ (Table 5). Such a high transported contribution indicates that the CFB is not only one of 


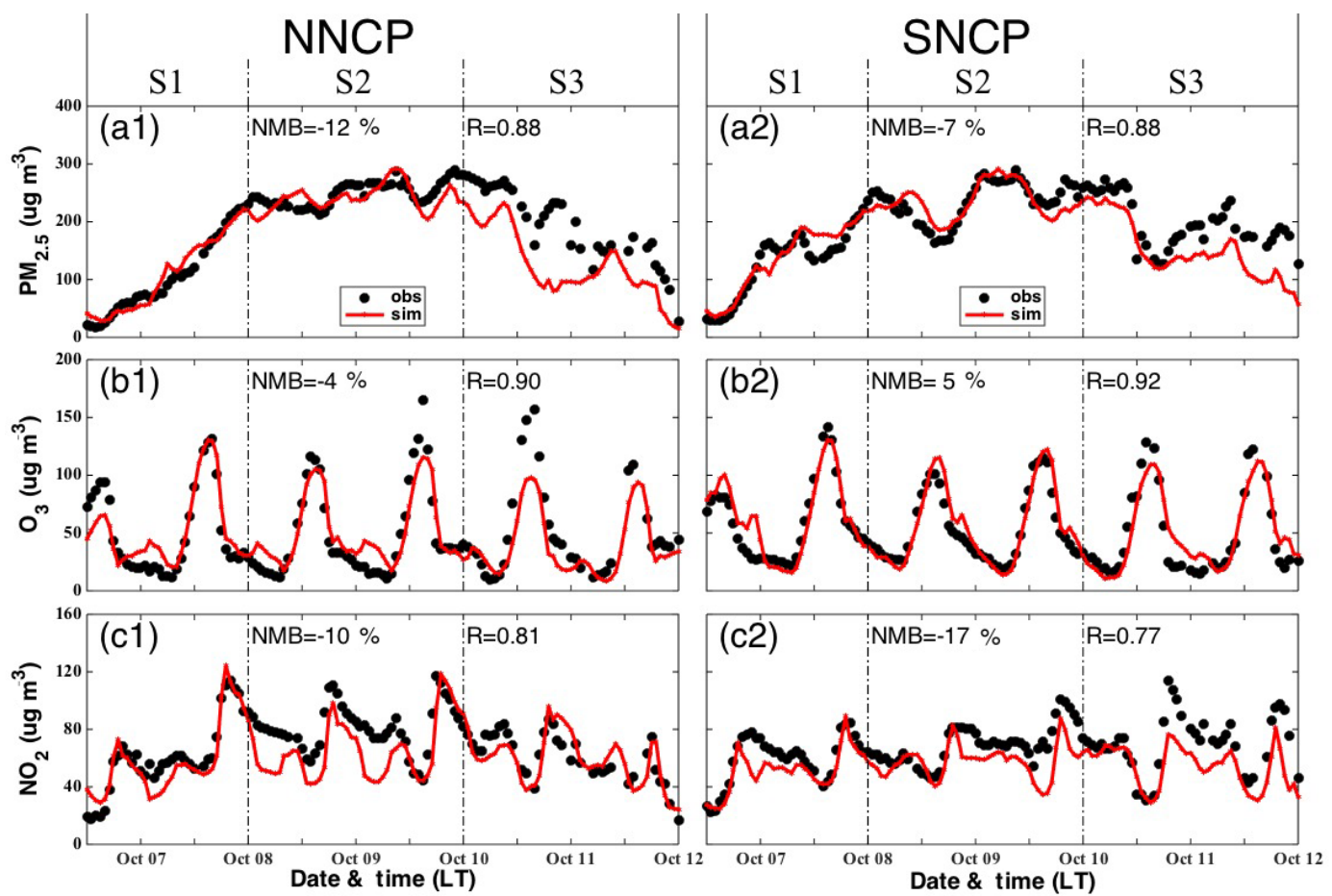

Figure 4. Regional average temporal variations in simulated (in red) and observed (in blue) results of species concentrations of (a) $\mathrm{PM}_{2.5}$ (b) $\mathrm{O}_{3}$ and (c) $\mathrm{NO}_{2}$ over the regions of NNCP and SNCP.

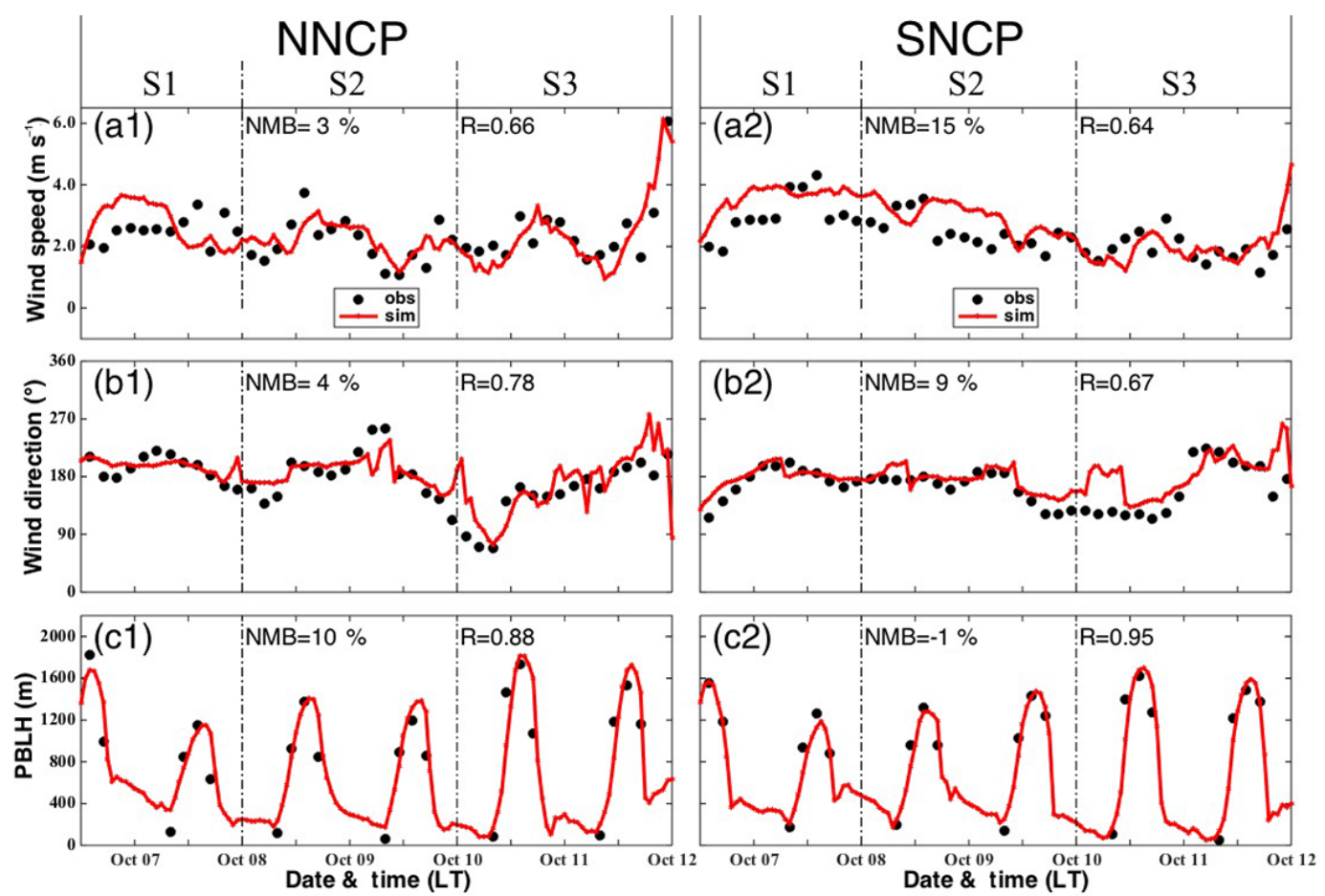

Figure 5. Regional average temporal variations in simulated (in red) and observed (in blue) results of meteorological parameters of (a) wind speed (b) wind direction and (c) PBLH over the regions of NNCP and SNCP. 


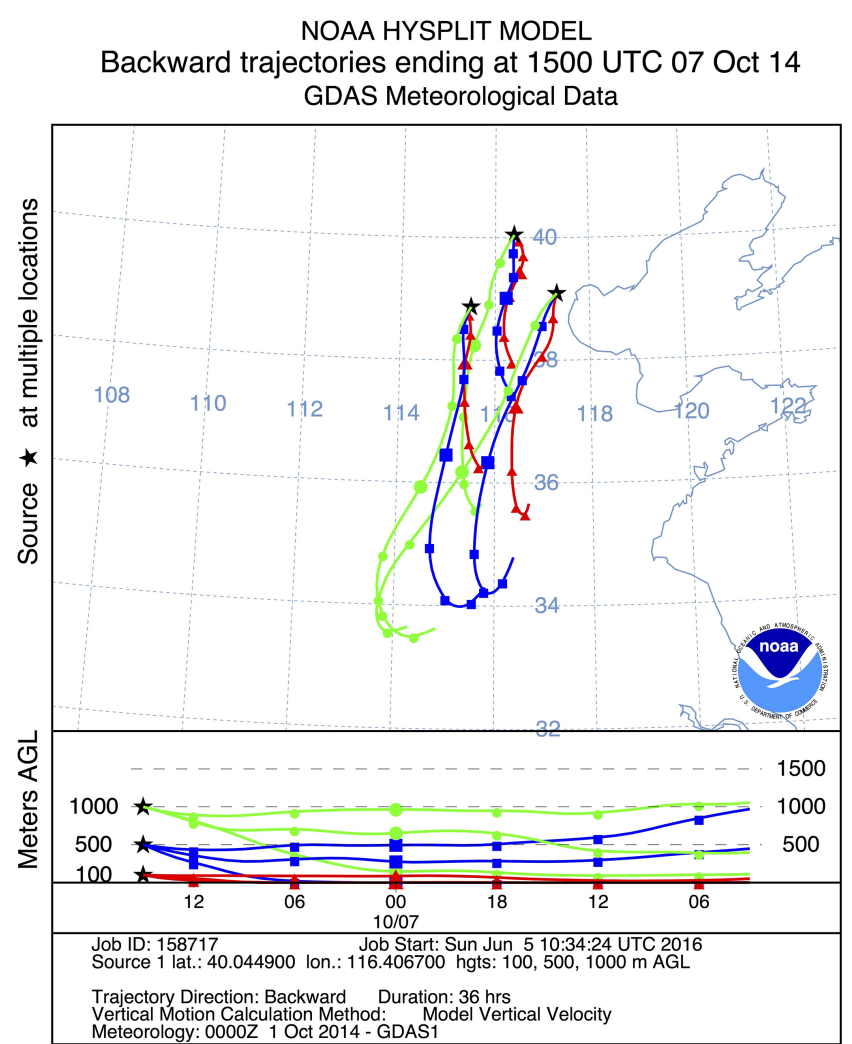

Figure 6. Backward trajectories of NNCP (Beijing, Tianjin and Baoding) during S1 (12:00-00:00 LT on 6-8 Oct) in different heights of 100,500 and $1000 \mathrm{~m}$.
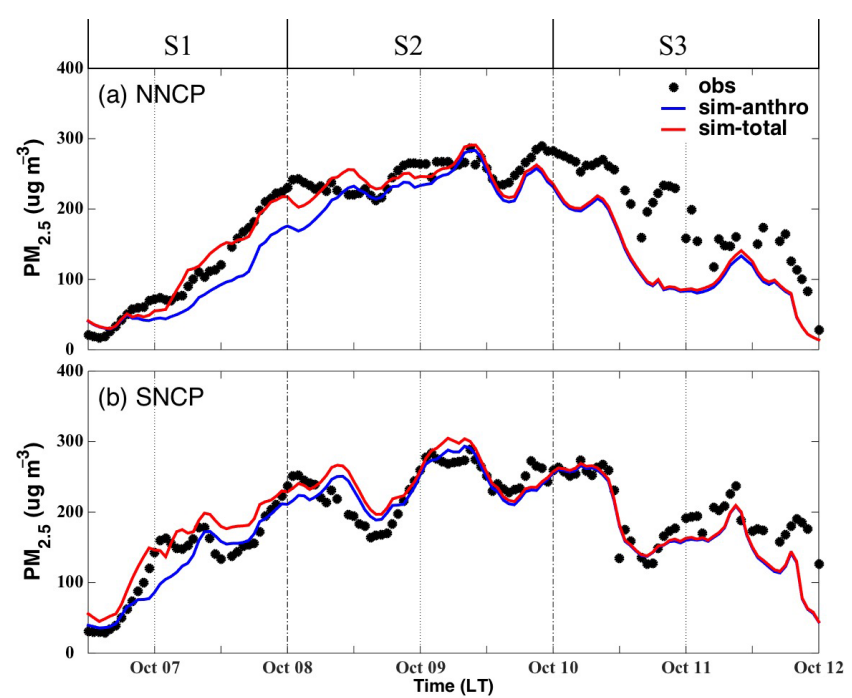

Figure 7. Hourly $\mathrm{PM}_{2.5}$ concentration of observations (obs) and simulations (sim-total and sim-anthro) in (a) NNCP and (b) SNCP; "sim-total" represents the simulations considering total emissions (anthropologic and crop field burning), whereas "sim-anthro" is the simulations only considering anthropologic emissions.

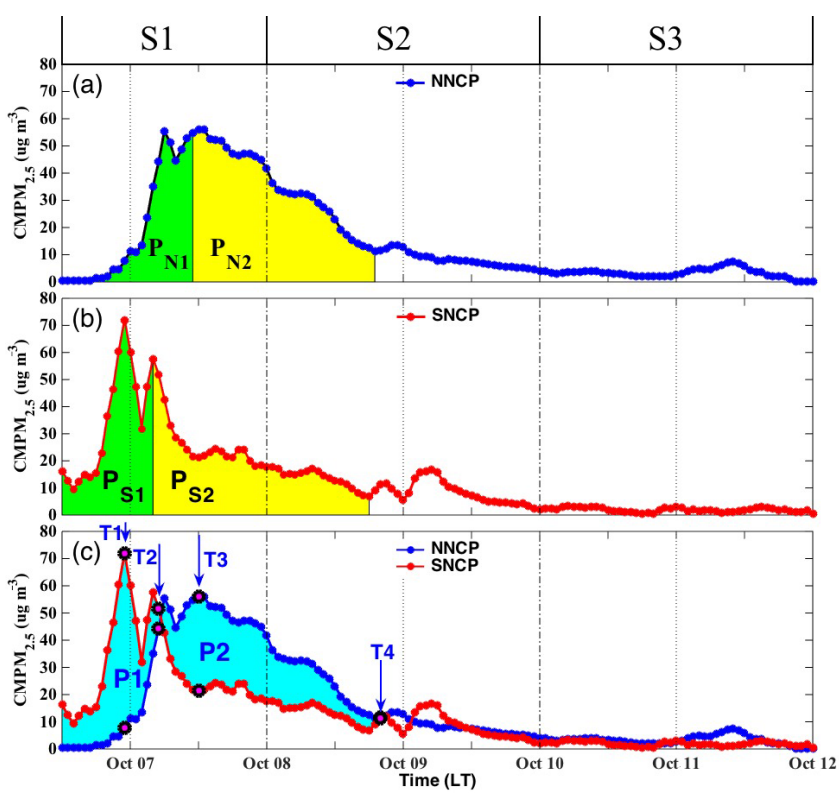

Figure 8. CFB contribution to $\mathrm{PM}_{2.5}$ concentration $\left(\mathrm{CPM}_{2.5}\right)(\mathbf{a})$ in SNCP, (b) in NNCP and (c) their comparison. The key point-inlocal-times of T1 (23:00, 6th), T2 (05:00, 7th), T3 (20:00, 7th) and T4 (19:00, 8th) are signed with blue arrow.

the significant local pollution sources, but also a considerable regional pollution source.

To clearly show the time evolution of the CFB effect on $\mathrm{PM}_{2.5}$ concentration, four time points were defined in Fig. 8c, such as T1 (23:00, 6 Oct), T2 (05:00, 7 Oct), T3 (20:00, 7 Oct) and T4 (19:00, 8 Oct). At T1, prominent CFB contribution occurred in SNCP with the highest value of $71.9 \mathrm{\mu g} \mathrm{m}^{-3}$, but accompanied with unimportant CFB contribution in NNCP with a low value of $7.7 \mu \mathrm{g} \mathrm{m}^{-3}$. At T2, the CFB contribution in SNCP decline with a relatively high value of $44.2 \mu \mathrm{g} \mathrm{m}^{-3}$, but a rise in NNCP with $51.6 \mu \mathrm{g} \mathrm{m}^{-3}$ (near the transition between P1 and P2). At T3, the CFB contribution rapidly decreases to a low value of $24.0 \mu \mathrm{g} \mathrm{m}^{-3}$ in SNCP, but increase to the highest with $47.0 \mu \mathrm{g} \mathrm{m}^{-3}$ in NNCP. At $\mathrm{T} 4$, the CFB contributions largely decrease, becoming lesser in both SCNP $\left(9.1 \mu \mathrm{g} \mathrm{m}^{-3}\right)$ and $\mathrm{NNCP}\left(11.4 \mu \mathrm{g} \mathrm{m}^{-3}\right)$. Interestingly, the $\mathrm{CFB}$ contribution in SNCP drops faster than that in NNCP (P2 in Fig. 8c), resulting in stronger effects in NNCP than in SNCP, as well as longer effects in NNCP.

To further understand the evolution of CFB to heavy haze pollution, we analyzed the horizontal distributions of $\mathrm{PM}_{2.5}$ concentration $\left(\mathrm{TPM}_{2.5}\right)$ and related CFB contribution $\left(\mathrm{CPM}_{2.5}\right)$ at $\mathrm{T} 1, \mathrm{~T} 2, \mathrm{~T} 3$ and T4 (Fig. 9). The pattern comparisons between simulated and observed near-surface $\mathrm{PM}_{2.5}$ concentrations $\left(\mathrm{TPM}_{2.5}\right.$ ) perform well (Fig. 9, left panels). Meanwhile, the regional average CFB contributions are shown in Table 6, including mass concentration and related percentage as well as the related time lag of NNCP corresponding to SNCP. At T1, massive local pollutants are 

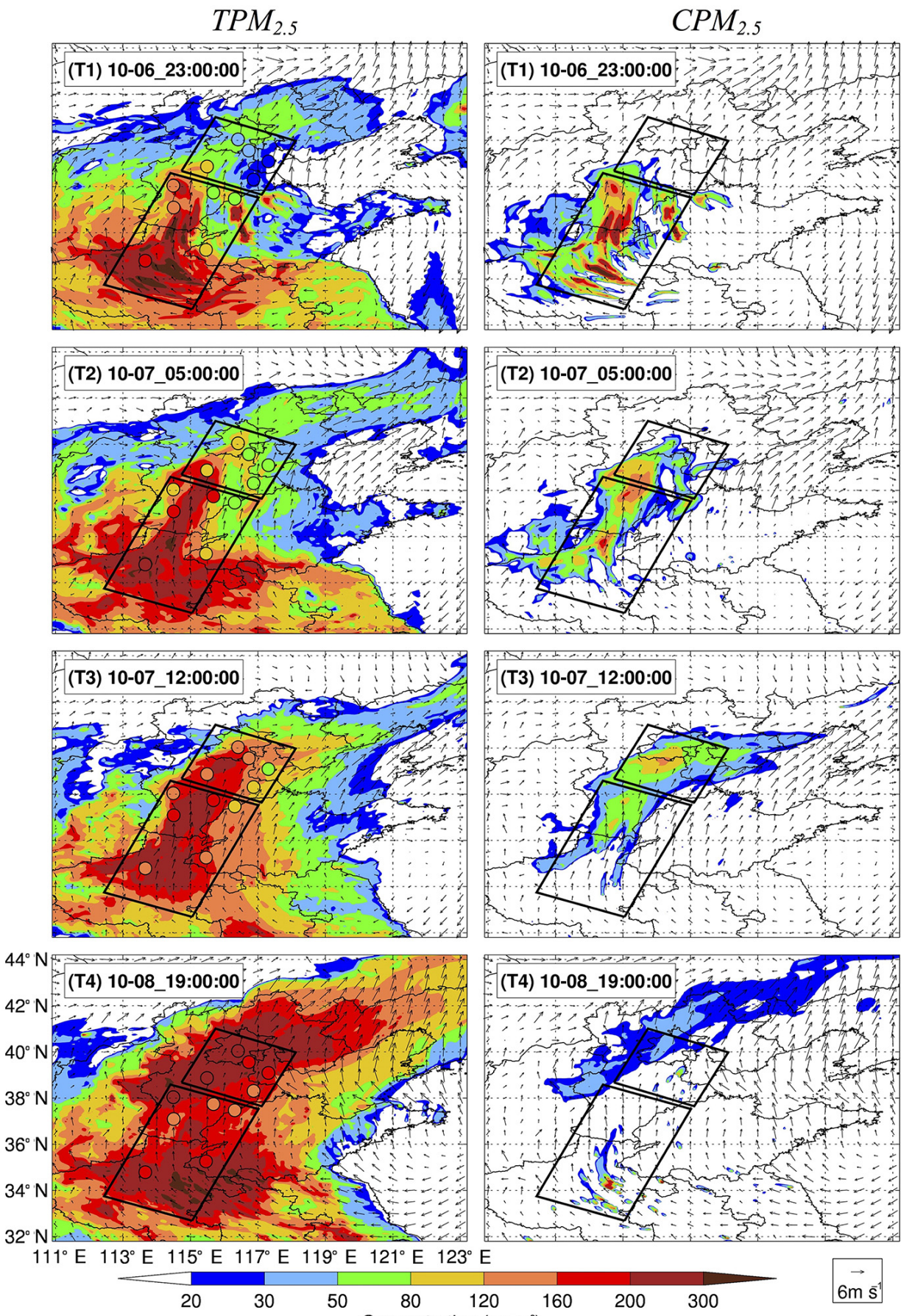

Figure 9. The distributions of $\mathrm{TPM}_{2.5}$ and $\mathrm{CPM}_{2.5}$ of the key point-in-local-times of $\mathrm{T} 1, \mathrm{~T} 2$, $\mathrm{T} 3$ and $\mathrm{T} 4$, which represent different pollution phases of emission from CFB to $\mathrm{PM}_{2.5}$. Left panels also show the pattern comparisons of simulated vs. observed near-surface PM 2.5 concentrations $\left(\mathrm{TPM}_{2.5}\right.$ ), with $\mathrm{PM}_{2.5}$ observations of colored circles. Black arrows denote simulated surface winds.

emitted from CFB in SNCP and the CFB plume had not yet been largely transported to NNCP (see $\mathrm{CPM}_{2.5}$ of Fig. 9 T1). The CFB contribution is high in SNCP with $72.6 \mu \mathrm{g} \mathrm{m}^{-3}$, accounting for $71 \%$ of the total $\mathrm{PM}_{2.5}$, whereas the CFB contribution is low with $8.1 \mu^{-3} \mathrm{~m}^{-3}$ in NNCP, only accounting for
$21 \%$. At T2, high CFB contribution occurred in both SNCP and NNCP with $37 \mu \mathrm{g} \mathrm{m}^{-3}$, suggesting that plenty of CFB pollutants were emitted from SNCP and were transported to NNCP (see $\mathrm{CPM}_{2.5}$ of Fig. 9 T2). At T3, CFB contribution rapidly reduced in SNCP with $20.2 \mu \mathrm{g} \mathrm{m}^{-3}(13 \%)$. It is worth 
Table 6. The regional average contribution of CFB in mass concentration and percentage, and the time lag of NNCP to SNCP for the four time points of T1 (23:00, 6 Oct), T2 (05:00, 7 Oct), T3 (20:00, 7 Oct) and T4 (19:00, 8 Oct).

\begin{tabular}{lrrrrr}
\hline Time & \multicolumn{2}{c}{ Mass $\left(\mu \mathrm{g} \mathrm{m}^{-3}\right)$} & \multicolumn{2}{c}{ Percentage } & Lag time (h) \\
& NNCP & SNCP & NNCP & SNCP & \\
\hline T1 & 8.1 & 72.6 & $21 \%$ & $71 \%$ & 7 \\
T2 & 36.7 & 36.5 & $73 \%$ & $27 \%$ & 8 \\
T3 & 50.4 & 20.2 & $58 \%$ & $13 \%$ & 11 \\
T4 & 13.4 & 10.3 & $6 \%$ & $5 \%$ & 12 \\
\hline
\end{tabular}

noting that the high CFB contribution with $50.4 \mu \mathrm{g} \mathrm{m}^{-3}$ $\left(58 \%\right.$ ) still remained in NNCP (see $\mathrm{CPM}_{2.5}$ of Fig. 9 T3). At T4, the CFB contribution largely decreased in both SNCP and NNCP (no more than $6 \%$ ) (see $\mathrm{CPM}_{2.5}$ of Fig. 9 T4). The time lag of NNCP to SNCP is $7-12 \mathrm{~h}$, and gradually increases from $\mathrm{T} 1$ to $\mathrm{T} 4$, implicating that the effect of $\mathrm{CFB}$ remains longer in NNCP than in SNCP. The highest $\mathrm{PM}_{2.5}$ concentrations are along the foothills of the Taihang Mountains (Left panels of Fig. 9), which may be related to the mountain effects.

\subsection{Impact of mountains}

Sensitivity experiments were conducted to quantify the impacts of the Taihang Mountains (referred as R-T), the Yanshan Mountains (R-Y) and both of them (R-TY) on heavy pollution. The mountains were removed from the model calculation, in which the altitude of mountains were reduced to the average altitude of NCP $(30 \mathrm{~m})$. With the reduction of altitudes of the topography, the dynamical conditions calculated from WRF-CHEM changed, which affect pollution transport, especially along the foothills of mountains. In this study, we utilized the differences between the simulations with or without mountains to represent the effect of the topography on $\mathrm{PM}_{2.5}$ concentration, which were calculated based on Eq. (9). As an online dynamical model, the topography changes in WRF-CHEM can lead to dynamical changes, such as the wind speeds at the foothills of the mountains. This is a useful and traditional sensitivity analysis method for numerical model to quantify the mountains effects, but with some shortcomings, which are to bring uncertainties to the sensitivity experiment. First, the impact of topography is too complicated to be completely quantified only by the altitude remove behavior. Second, the initial NCEP FNL data with mountains are treated as "real" in scenarios without mountains. The sensitive configuration and related enclosing scope are displayed in Fig. S2.

$\mathrm{IPM}_{2.5}=\mathrm{RPM}_{2.5}-\mathrm{TPM}_{2.5}$,

where $\mathrm{IPM}_{2.5}$ is the net impacts of mountains on $\mathrm{PM}_{2.5}$; $\mathrm{RPM}_{2.5}$ denotes the simulated $\mathrm{PM}_{2.5}$ concentration with removal behaviors, involving R-TY, R-T and R-Y; $\mathrm{TPM}_{2.5}$ rep-

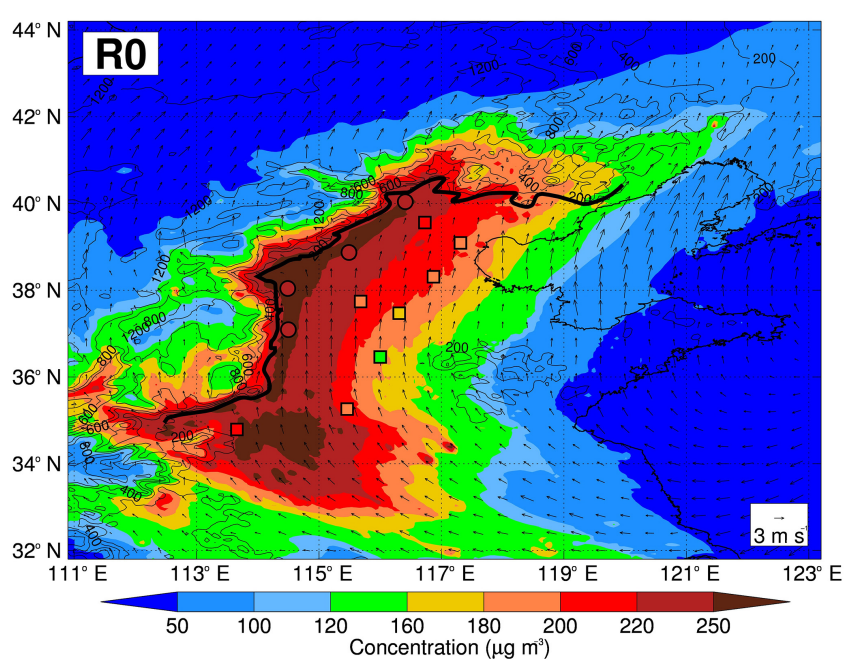

Figure 10. The elevation contours and the pattern comparisons of simulated vs. observed near-surface $\mathrm{PM}_{2.5}$ concentrations from 12:00 to 00:00 LT on 7 to 10 Oct. Colored circles: $\mathrm{PM}_{2.5}$ observations of foothill sites; Colored squares: $\mathrm{PM}_{2.5}$ observations of nonfoothill sites; Black arrows: simulated surface winds. The $200 \mathrm{~m}$ contour was highlighted with bold black line.

resents the simulated $\mathrm{PM}_{2.5}$ concentration considering emission of anthropologic and $\mathrm{CFB}$, which corresponds to the case of R0 (Fig. S2a).

The sensitivity study period was selected from 12:00 to 00:00 LT on 7 to 10 October. Figure 10 displays the elevation contours and the horizontal distributions of $\mathrm{PM}_{2.5}$ concentration with the effect of mountains, exhibiting a good performance of the pattern comparisons between simulated and observed near-surface $\mathrm{PM}_{2.5}$ concentrations. The results illustrate that the mountains had important impacts on regional $\mathrm{PM}_{2.5}$ concentration, especially for the region along the foothills of mountains with a heavy pollution area, covering sampling sites of $\mathrm{BJ}, \mathrm{BD}, \mathrm{SJZ}$ and XT. Here, it is attributed to the mountain blocking effect, which has two categories of influences. First, the mountains block the airflows, causing pollutant accumulation and resulting in high $\mathrm{PM}_{2.5}$ loading at the foothills of mountains (influence-1, block). Second, the mountains redirect the airflows, causing the pollutants to move toward the downwind foothill areas (influence-2, redirect). Both influences act to prevent the pollutant plume to disperse toward western mountains, causing accumulations of the air pollutants along the foothills of mountains. These two influences of mountain blocking effects are illustrated as schematic pictures in Fig. S3.

Figure 11 displays the simulated $\mathrm{PM}_{2.5}$ concentration due to the mountain effects $\left(\mathrm{RPM}_{2.5}\right)$, with the three cases (R-TY, $\mathrm{R}-\mathrm{T}$ and R-Y). The heavy pollution accumulation (Fig. 10) along the foothills of mountains is significantly reduced, especially with the removal of Taihang Mountains (R-T and R-TY) (Fig. 11 a1 and a2). In these two cases, the pollution plumes dispersed westerly (Fig. $11 \mathrm{~b} 1$ and b2). The 

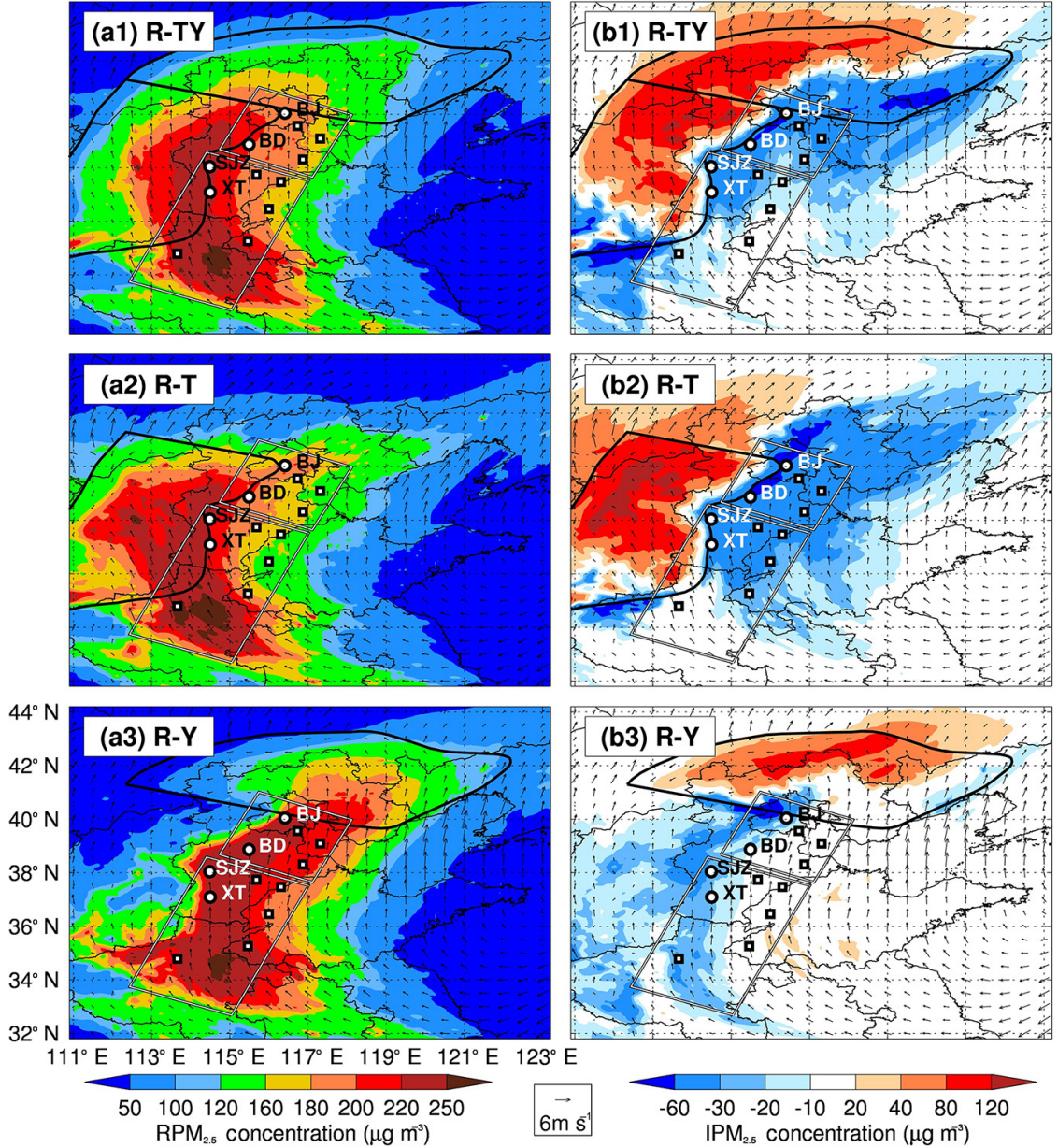

Figure 11. The average spatial distribution of $\mathrm{PM}_{2.5}$ concentration and horizontal winds during 12:00 to 00:00 LT on 7 to 10 Oct. (a) Simulated $\mathrm{PM}_{2.5}$ loading with remove behaviors $\mathrm{RPM}_{2.5}$, involving R-TY, R-T and R-Y. (b) The related impacts of mountains on $\mathrm{PM}_{2.5}$ (IPM 2.5 ), which represent the effect of related mountains. The bold black lines were used to stress enclosing scope of each remove behavior.

$\mathrm{PM}_{2.5}$ concentrations increase $40-120 \mu \mathrm{g} \mathrm{m}^{-3}$ in the western part of Taihang Mountains, and reduce $20-60 \mu \mathrm{g} \mathrm{m}^{-3}$ in NCP. The distribution of the reduced pollution plume shows a northeast band plume, indicating the mountain blocking effect. With the removal of the Yanshan Mountains (R-Y), the high $\mathrm{PM}_{2.5}$ concentrations still remained along the foothills of the Taihang Mountains (Fig. 11 a3), but more pollutants are pushed forward along the foothill, toward the northeastern NCP. Without the blocking effect of the Yanshan Mountains, the $\mathrm{PM}_{2.5}$ concentrations increased $20-80 \mu \mathrm{g} \mathrm{m} \mathrm{m}^{-3}$ in the northern part of the Yanshan Mountains, and decreased $10-60 \mu \mathrm{g} \mathrm{m}^{-3}$ in the southern part of the Yanshan Mountains (Fig. 11 b3).

In the foothill sampling sites (BJ, BD, SJZ and XT), the average $\mathrm{PM}_{2.5}$ concentrations are reduced $54.2 \mu \mathrm{g} \mathrm{m}^{-3}$ for the case of R-T, which is much higher than the case of R$\mathrm{Y}\left(28.4 \mu \mathrm{g} \mathrm{m}^{-3}\right)$. For the other non-foothill sites, the average reduction is $34.7 \mu \mathrm{g} \mathrm{m}^{-3}$ for the case of R-T, which is also much higher than the case of R-Y $\left(2.4 \mu \mathrm{g} \mathrm{m}^{-3}\right)$, sug- gesting that the Taihang Mountains have stronger effects than the Yanshan Mountains. Meanwhile, the higher impacts in the foothill sampling sites than non-foothill sites are further demonstrated.

\section{Conclusions}

In recent years, the NCP region, including the capital city of Beijing, has suffered serious haze pollution problem, especially in winter and summer. Most studies concerned about the intense secondary formation, huge regional transport of pollutants, stationary meteorological conditions and large local emission. In autumn, CFB and movement of wind based on large-scale topography are important in $\mathrm{NCP}$, whereas the percentage of transported CFB emission sources are seldom specified. This probably resulted from the contingency of CFB activities during harvest period and the limitation of temporal resolution of CFB emission inventories. In this study, we extracted a more detailed CFB emission inventory 
based on the provincial statistical data and CFB activities captured by MODIS. The WRF-CHEM mode was applied to study the effect of $\mathrm{CFB}$ on the $\mathrm{PM}_{2.5}$ concentrations in $\mathrm{NCP}$, especially the evaluation of CFB plums pollution, such as local influence and long-range transportation. We get some insights of how could CFB affect the air quality in NNCP and Beijing under heavy haze condition, though more and longer studies are needed to get more representative conclusions. The results are summarized:

1. A more detailed CFB emission inventory was generated in NCP. The daily CFB emissions were estimated depending on CFB activities captured by MODIS. Plenty of pollutants emitted from SNCP on 6 and 7 October, producing plenty of $\mathrm{PM}_{2.5}$ pollution, but few in NNCP during the entire haze period.

2. The WRF-CHEM model reproduced the pollution episode with a good agreement with observations. The correlation coefficients $(R)$ of simulated and measured $\mathrm{PM}_{2.5}$ concentration are 0.88 in both NNCP and SNCP, and the related NMB are $-12 \%$ in NNCP and $-7 \%$ in SNCP. The simulated winds and PBLH are also in good agreement with observations in both NNCP and SNCP.

3. The WRF-CHEM model was used to investigate the impacts of CFB contribution and its evaluation on $\mathrm{PM}_{2.5}$ concentration. The SNCP region is mainly influenced by the local CFB emissions, causing a maximum of $34 \% \mathrm{PM}_{2.5}$ increase. Whereas the NNCP region is mainly affected by the long-range transport of pollution plume emitted from CFB in SNCP, causing a maximum of $32 \% \mathrm{PM}_{2.5}$ increase in NNCP.
4. The research domain includes two regions of interests. One is the NNCP, including two mega cities (Beijing and Tianjin), where few CFBs occurred. Another is the SNCP, where substantial CFB occurred. This study shows that there is a substantially long-range transport of CFB plume from SNCP to NNCP. More importantly, the effect of CFB remains longer in NNCP than in SNCP along the foothill areas of the Taihang Mountains, causing significant enhancement in Beijing in both time and magnitude.

5. Another major finding is that the mountains, surrounding the NCP in the north and west, play significant roles in enhancing the $\mathrm{PM}_{2.5}$ pollution in NNCP through the blocking effect. Mountains block and redirect the airflows, causing the pollution accumulation along the foothills of mountains. The Taihang Mountains had greater impacts on $\mathrm{PM}_{2.5}$ concentration than the Yanshan Mountains.

On account of various factors, such as pollutant long-range transport and pollutant accumulation caused by mountain effects, the prohibition of CFB should be strict not only in or around Beijing, but also on the ulterior crop growth areas of SNCP. Other $\mathrm{PM}_{2.5}$ emissions in the SNCP should be significantly limited in order to reduce the occurrences of heavy haze events in NNCP region, including the Beijing City. 


\section{Data availability}

1. The real-time $\mathrm{NO}_{2}, \mathrm{O}_{3}$ and $\mathrm{PM}_{2.5}$ are accessible for the public on the website http://106.37.208.233:20035/. One can also access the historic profile of observed ambient pollutants through visiting http://www.aqistudy. $\mathrm{cn} /$.

2. The reanalysis meteorological data, including wind direction, wind speed and planetary boundary layer height (PBLH) are obtained from the European Centre for Medium-range Weather Forecasts (ECMWF), for the public on the website: http://apps.ecmwf.int/datasets/ data/interim-full-daily/levtype $=$ sfc/.

3. The MODIS Land Cover products are accessible for the public on the website https://lpdaac.usgs.gov/dataset_ discovery/modis/modis_products_table.

4. The MODIS Fire products are accessible for the public on the website https://firms.modaps.eosdis.nasa.gov/ download/.

5. The MODIS true color map are accessible for the public on the website https://worldview.earthdata.nasa.gov/.

\section{The Supplement related to this article is available online at doi:10.5194/acp-16-9675-2016-supplement.}

Acknowledgements. The PBL height and wind field data were obtained from the European Centre for Medium-Range Weather Forecasts (ECMWF) website (http://www.ecmwf.int/products/data/). This work is supported by the National Natural Science Foundation of China (NSFC) under grant nos. 41275186 and 41430424, and the Open Fund of the State Key Laboratory of Loess and Quaternary Geology (SKLLQG1413). The National Center for Atmospheric Research is sponsored by the National Science Foundation.

Edited by: H. Su

\section{References}

Akagi, S. K., Yokelson, R. J., Wiedinmyer, C., Alvarado, M. J., Reid, J. S., Karl, T., Crounse, J. D., and Wennberg, P. O.: Emission factors for open and domestic biomass burning for use in atmospheric models, Atmos. Chem. Phys., 11, 4039-4072, doi:10.5194/acp-11-4039-2011, 2011.

Andreae, M. O. and Merlet, P.: Emission of trace gases and aerosols from biomass burning, Global Biogeochem. Cy., 15, 955-966, 2001

Baek, J., Hu, Y., Odman, M. T., and Russell, A. G.: Modeling secondary organic aerosol in CMAQ using multigenerational oxidation of semi-volatile organic compounds, J. Geophys. Res.Atmos., 116, D22204, doi:10.1029/2011JD015911, 2011.
Bi, Y., Wang, Y., and Cao, C.: Straw Resource Quantity and its Regional Distribution in China [J], Journal of Agricultural Mechanization Research, 3, 1-7-, 2010.

Binkowski, F. S. and Roselle, S. J.: Models-3 Community Multiscale Air Quality (CMAQ) model aerosol component 1. Model description, J. Geophys. Res.-Atmos., 108, 4183, doi:10.1029/2001JD001409, 2003.

Cao, G., Zhang, X., Wang, Y., and Zheng, F.: Estimation of emissions from field burning of crop straw in China, Chinese Sci. Bull., 53, 784-790, 2008.

Chang, J., Brost, R., Isaksen, I., Madronich, S., Middleton, P., Stockwell, W., and Walcek, C.: A three-dimensional Eulerian acid deposition model: Physical concepts and formulation, J. Geophys. Res.-Atmos., 92, 14681-14700, 1987.

Chen, F. and Dudhia, J.: Coupling an advanced land surfacehydrology model with the Penn State-NCAR MM5 modeling system. Part I: Model implementation and sensitivity, Mon. Weather Rev., 129, 569-585, 2001.

Chen, Y., Zhao, C., Zhang, Q., Deng, Z., Huang, M., and Ma, X.: Aircraft study of mountain chimney effect of Beijing, china, J. Geophys. Res.-Atmos., 114, D08306, doi:10.1029/2008JD010610, 2009.

Cheng, Y., Engling, G., He, K.-B., Duan, F.-K., Ma, Y.-L., Du, Z.Y., Liu, J.-M., Zheng, M., and Weber, R. J.: Biomass burning contribution to Beijing aerosol, Atmos. Chem. Phys., 13, 77657781, doi:10.5194/acp-13-7765-2013, 2013.

Cheng, Z., Wang, S., Fu, X., Watson, J. G., Jiang, J., Fu, Q., Chen, C., Xu, B., Yu, J., Chow, J. C., and Hao, J.: Impact of biomass burning on haze pollution in the Yangtze River delta, China: a case study in summer 2011, Atmos. Chem. Phys., 14, 45734585, doi:10.5194/acp-14-4573-2014, 2014.

Emmons, L. K., Walters, S., Hess, P. G., Lamarque, J.-F., Pfister, G. G., Fillmore, D., Granier, C., Guenther, A., Kinnison, D., Laepple, T., Orlando, J., Tie, X., Tyndall, G., Wiedinmyer, C., Baughcum, S. L., and Kloster, S.: Description and evaluation of the Model for Ozone and Related chemical Tracers, version 4 (MOZART-4), Geosci. Model Dev., 3, 43-67, doi:10.5194/gmd3-43-2010, 2010.

Friedl, M. A., Sulla-Menashe, D., Tan, B., Schneider, A., Ramankutty, N., Sibley, A., and Huang, X.: MODIS Collection 5 global land cover: Algorithm refinements and characterization of new datasets, Remote Sens. Environ., 114, 168-182, 2010.

Giglio, L., Descloitres, J., Justice, C. O., and Kaufman, Y. J.: An enhanced contextual fire detection algorithm for MODIS, Remote Sens. Environ., 87, 273-282, 2003.

Grell, G. A., Peckham, S. E., Schmitz, R., McKeen, S. A., Frost, G. Skamarock, W. C., and Eder, B.: Fully coupled "online" chemistry within the WRF model, Atmos. Environ., 39, 6957-6975, 2005.

Guan, D., Su, X., Zhang, Q., Peters, G. P., Liu, Z., Lei, Y., and He, K.: The socioeconomic drivers of China's primary $\mathrm{PM}_{2.5}$ emissions, Environ. Res. Lett., 9, 024010, doi:10.1088/17489326/9/2/024010, 2014.

Guenther, A., Karl, T., Harley, P., Wiedinmyer, C., Palmer, P. I., and Geron, C.: Estimates of global terrestrial isoprene emissions using MEGAN (Model of Emissions of Gases and Aerosols from Nature), Atmos. Chem. Phys., 6, 3181-3210, doi:10.5194/acp-63181-2006, 2006. 
Hao, W.-M. and Liu, M.-H.: Spatial and temporal distribution of tropical biomass burning, Global Biogeochem. Cy., 8, 495-503, 1994.

He, H., Tie, X., Zhang, Q., Liu, X., Gao, Q., Li, X., and Gao, Y.: Analysis of the causes of heavy aerosol pollution in Beijing, China: A case study with the WRF-CHEM model, Particuology, 20, 32-40, 2015.

Hong, J., Ren, L., Hong, J., and Xu, C.: Environmental impact assessment of corn straw utilization in China, J. Clean. Prod., 30, 1e9, doi:10.1016/j.jclepro.2015.02.081, 2015.

Hong, S.-Y., Noh, Y., and Dudhia, J.: A new vertical diffusion package with an explicit treatment of entrainment processes, Mon. Weather Rev., 134, 2318-2341, 2006.

Hu, X.-M., Ma, Z., Lin, W., Zhang, H., Hu, J., Wang, Y., Xu, X., Fuentes, J. D., and Xue, M.: Impact of the Loess Plateau on the atmospheric boundary layer structure and air quality in the North China Plain: A case study, Sci. Total Environ., 499, 228-237, 2014.

Huang, X., Li, M., Li, J., and Song, Y.: A high-resolution emission inventory of crop burning in fields in China based on MODIS Thermal Anomalies/Fire products, Atmos. Environ., 50, 9-15, 2012.

Jiang, C., Wang, H., Zhao, T., Li, T., and Che, H.: Modeling study of $\mathrm{PM}_{2.5}$ pollutant transport across cities in China's Jing-JinJi region during a severe haze episode in December 2013, Atmos. Chem. Phys., 15, 5803-5814, doi:10.5194/acp-15-58032015, 2015.

Koppmann, R., von Czapiewski, K., and Reid, J. S.: A review of biomass burning emissions, part I: gaseous emissions of carbon monoxide, methane, volatile organic compounds, and nitrogen containing compounds, Atmos. Chem. Phys. Discuss., 5, 1045510516, doi:10.5194/acpd-5-10455-2005, 2005.

Li, G., Zhang, R., Fan, J., and Tie, X.: Impacts of black carbon aerosol on photolysis and ozone, J. Geophys. Res.-Atmos., 110, D23206, doi:10.1029/2005JD005898, 2005.

Li, G., Lei, W., Zavala, M., Volkamer, R., Dusanter, S., Stevens, P., and Molina, L. T.: Impacts of HONO sources on the photochemistry in Mexico City during the MCMA-2006/MILAGO Campaign, Atmos. Chem. Phys., 10, 6551-6567, doi:10.5194/acp-106551-2010, 2010.

Li, G., Bei, N., Tie, X., and Molina, L. T.: Aerosol effects on the photochemistry in Mexico City during MCMA2006/MILAGRO campaign, Atmos. Chem. Phys., 11, 51695182, doi:10.5194/acp-11-5169-2011, 2011.

Li, G., Lei, W., Bei, N., and Molina, L. T.: Contribution of garbage burning to chloride and $\mathrm{PM}_{2.5}$ in Mexico City, Atmos. Chem. Phys., 12, 8751-8761, doi:10.5194/acp-12-8751-2012, 2012.

Li, L., Wang, Y., Zhang, Q., Li, J., Yang, X., and Jin, J.: Wheat straw burning and its associated impacts on Beijing air quality, Sci. China Ser. D, 51, 403-414, 2008.

Lin, Y.-L., Farley, R. D., and Orville, H. D.: Bulk parameterization of the snow field in a cloud model, J. Clim. Appl. Meteorol., 22, 1065-1092, 1983.

Liu, S., Liu, Z., Li, J., Wang, Y., Ma, Y., Sheng, L., Liu, H., Liang, F., Xin, G., and Wang, J.: Numerical simulation for the coupling effect of local atmospheric circulations over the area of Beijing, Tianjin and Hebei Province, Sci. China Ser. D, 52, 382-392, 2009.
Lu, Z., Zhang, Q., and Streets, D. G.: Sulfur dioxide and primary carbonaceous aerosol emissions in China and India, 1996-2010, Atmos. Chem. Phys., 11, 9839-9864, doi:10.5194/acp-11-98392011, 2011.

Miao, Y., Liu, S., Zheng, Y., Wang, S., and Chen, B.: Numerical study of the effects of topography and urbanization on the local atmospheric circulations over the Beijing-Tianjin-Hebei, China, Adv. Meteorol., 2015, 1-16, doi:10.1155/2015/397070, 2015.

Miao, Y., Liu, S., Zheng, Y., and Wang, S.: Modeling the feedback between aerosol and boundary layer processes: a case study in Beijing, China, Environ. Sci. Pollut. R., 23, 3342-3357, doi:10.1007/s11356-015-5562-8, 2016.

Mukai, S., Yasumoto, M., and Nakata, M.: Estimation of biomass burning influence on air pollution around Beijing from an aerosol retrieval model, Thescientificworldjo., 2014, 1-10, doi:10.1155/2014/649648, 2014.

National Bureau of Statistics (NBS), China Statistical Yearbook 2014, China Statistics Press, Beijing, available at: http://www. stats.gov.cn/tjsj/ndsj/2015/indexch.htm, 2015.

Ni, H., Han, Y., Cao, J., Chen, L.-W. A., Tian, J., Wang, X., Chow, J. C., Watson, J. G., Wang, Q., and Wang, P.: Emission characteristics of carbonaceous particles and trace gases from open burning of crop residues in China, Atmos. Environ., 123, 399-406, 2015.

Qin, S.-G., Ding, A., and Wang, T.: Transport pattern of biomass burnings air masses in Eurasia and the impacts on China, China Environ. Sci., 26, 641-645, 2006.

Shi, T., Liu, Y., Zhang, L., Hao, L., and Gao, Z.: Burning in agricultural landscapes: an emerging natural and human issue in China, Landscape Ecology, 29, 1785-1798, 2014.

Shon, Z.-H.: Long-term variations in $\mathrm{PM}_{2.5}$ emission from open biomass burning in Northeast Asia derived from satellite-derived data for 2000-2013, Atmos. Environ., 107, 342-350, 2015.

Song, Y., Tang, X., Xie, S., Zhang, Y., Wei, Y., Zhang, M., Zeng, L., and $\mathrm{Lu}$, S.: Source apportionment of $\mathrm{PM}_{2.5}$ in Beijing in 2004, J. Hazard. Mater., 146, 124-130, 2007.

Stockwell, W. R., Middleton, P., Chang, J. S., and Tang, X.: The second generation regional acid deposition model chemical mechanism for regional air quality modeling, J. Geophys. Res.-Atmos., 95, 16343-16367, 1990.

Streets, D., Yarber, K., Woo, J. H., and Carmichael, G.: Biomass burning in Asia: Annual and seasonal estimates and atmospheric emissions, Global Biogeochem. Cy., 17, 1099, doi:10.1029/2003GB002040, 2003.

Su, J., Zhu, B., Kang, H., Wang, H., and Wang, T.: Applications of pollutants released form crop residues at open burning in Yangtze River Delta region in air quality model, Environ. Sci., 33, 14181424, 2012.

Sun, Y., Song, T., Tang, G., and Wang, Y.: The vertical distribution of $\mathrm{PM}_{2.5}$ and boundary-layer structure during summer haze in Beijing, Atmos. Environ., 74, 413-421, 2013.

Tie, X., Madronich, S., Walters, S., Zhang, R., Rasch, P., and Collins, W.: Effect of clouds on photolysis and oxidants in the troposphere, J. Geophys. Res.-Atmos., 108, 4642, doi:10.1029/2003JD003659, 2003.

Tie, X., Madronich, S., Walters, S., Edwards, D. P., Ginoux, P., Mahowald, N., Zhang, R., Lou, C., and Brasseur, G.: Assessment of the global impact of aerosols on tropospheric oxidants, J. Geophys. Res.-Atmos., 110, D03204, doi:10.1029/2004JD005359, 2005. 
Tie, X., Madronich, S., Li, G., Ying, Z., Zhang, R., Garcia, A. R., Lee-Taylor, J., and Liu, Y.: Characterizations of chemical oxidants in Mexico City: A regional chemical dynamical model (WRF-CHEM) study, Atmos. Environ., 41, 1989-2008, 2007.

Tie, X., Geng, F., Peng, L., Gao, W., and Zhao, C.: Measurement and modeling of $\mathrm{O}_{3}$ variability in Shanghai, China: Application of the WRF-CHEM model, Atmos. Environ., 43, 4289-4302, 2009

Tie, X., Zhang, Q., He, H., Cao, J., Han, S., Gao, Y., Li, X., and Jia, X. C.: A budget analysis of the formation of haze in Beijing, Atmos. Environ., 100, 25-36, 2015.

van der Werf, G. R., Randerson, J. T., Giglio, L., Collatz, G. J., Kasibhatla, P. S., and Arellano Jr., A. F.: Interannual variability in global biomass burning emissions from 1997 to 2004, Atmos. Chem. Phys., 6, 3423-3441, doi:10.5194/acp-6-3423-2006, 2006.

Wang, L., Xu, J., Yang, J., Zhao, X., Wei, W., Cheng, D., Pan, X., and $\mathrm{Su}, \mathrm{J} .:$ Understanding haze pollution over the southern Hebei area of China using the CMAQ model, Atmos. Environ., 56, 6979, 2012.

Wang, L. T., Wei, Z., Yang, J., Zhang, Y., Zhang, F. F., Su, J., Meng, C. C., and Zhang, Q.: The 2013 severe haze over southern Hebei, China: model evaluation, source apportionment, and policy implications, Atmos. Chem. Phys., 14, 3151-3173, doi:10.5194/acp-14-3151-2014, 2014

Wang, Q., Shao, M., Liu, Y., William, K., Paul, G., Li, X., Liu, Y., and Lu, S.: Impact of biomass burning on urban air quality estimated by organic tracers: Guangzhou and Beijing as cases, Atmos. Environ., 41, 8380-8390, 2007.

Wang, Q., Shao, M., Zhang, Y., Wei, Y., Hu, M., and Guo, S.: Source apportionment of fine organic aerosols in Beijing, Atmos. Chem. Phys., 9, 8573-8585, doi:10.5194/acp-9-8573-2009, 2009.

Wang, L. T., Wei, Z., Yang, J., Zhang, Y., Zhang, F. F., Su, J., Meng, C. C., and Zhang, Q.: The 2013 severe haze over southern Hebei, China: model evaluation, source apportionment, and policy implications, Atmos. Chem. Phys., 14, 3151-3173, doi:10.5194/acp-14-3151-2014, 2014.

Wang, S. and Zhang, C.: Spatial and temporal distribution of air pollutant emissions from open burning of crop residues in China, Sciencepaper online, 3, 329-333, 2008.

Wang, W., Maenhaut, W., Yang, W., Liu, X., Bai, Z., Zhang, T., Claeys, M., Cachier, H., Dong, S., and Wang, Y.: One-year aerosol characterization study for $\mathrm{PM}_{2.5}$ and $\mathrm{PM}_{10}$ in Beijing, Atmos. Pollut. Res., 5, 554-562, 2014.

Wesely, M.: Parameterization of surface resistances to gaseous dry deposition in regional-scale numerical models, Atmos. Environ., 23, 1293-1304, 1989.

Wiedinmyer, C., Akagi, S. K., Yokelson, R. J., Emmons, L. K., AlSaadi, J. A., Orlando, J. J., and Soja, A. J.: The Fire INventory from NCAR (FINN): a high resolution global model to estimate the emissions from open burning, Geosci. Model Dev., 4, 625641, doi:10.5194/gmd-4-625-2011, 2011.

Yan, X., Ohara, T., and Akimoto, H.: Bottom-up estimate of biomass burning in mainland China, Atmos. Environ., 40, 52625273, 2006.
Yang, H., Liu, M., and Liufu, Y.: Research and simulation of straw crop burning in Anhui and Henan Provinces using CALPUFF, Res. Environ. Sci., 23, 1368-1375, 2010 (in Chinese).

Yang, Y. R., Liu, X. G., Qu, Y., An, J. L., Jiang, R., Zhang, Y. H., Sun, Y. L., Wu, Z. J., Zhang, F., Xu, W. Q., and Ma, Q. X.: Characteristics and formation mechanism of continuous hazes in China: a case study during the autumn of 2014 in the North China Plain, Atmos. Chem. Phys., 15, 8165-8178, doi:10.5194/acp-158165-2015, 2015.

Yao, L., Yang, L., Yuan, Q., Yan, C., Dong, C., Meng, C., Sui, X., Yang, F., Lu, Y., and Wang, W.: Sources apportionment of $\mathrm{PM}_{2.5}$ in a background site in the North China Plain, Sci. Total Environ., 541, 590-598, 2016.

Yevich, R. and Logan, J. A.: An assessment of biofuel use and burning of agricultural waste in the developing world, Global Biogeochem. Cy., 17, 1095, doi:10.1029/2002GB001952, 2003.

Zha, S., Zhang, S., Cheng, T., Chen, J., Huang, G., Li, X., and Wang, Q.: Agricultural fires and their potential impacts on regional air quality over China, Aerosol Air Qual. Res., 13, 992-1001, 2013.

Zhang, H.: A laboratory study on emission characteristics of gaseous and particulate pollutants emitted from agricultural crop residue burning in China, PhD Thesis, Fudan University, China, 2009.

Zhang, L., Liu, Y., and Hao, L.: Contributions of open crop straw burning emissions to $\mathrm{PM}_{2.5}$ concentrations in China, Environ. Res. Lett., 11, 014014, doi:10.1088/1748-9326/11/1/014014, 2016.

Zhang, Q., Streets, D. G., Carmichael, G. R., He, K. B., Huo, H., Kannari, A., Klimont, Z., Park, I. S., Reddy, S., Fu, J. S., Chen, D., Duan, L., Lei, Y., Wang, L. T., and Yao, Z. L.: Asian emissions in 2006 for the NASA INTEX-B mission, Atmos. Chem. Phys., 9, 5131-5153, doi:10.5194/acp-9-5131-2009, 2009.

Zhang, Y.-L. and Cao, F.: Is it time to tackle $\mathrm{PM}_{2.5}$ air pollutions in China from biomass-burning emissions?, Environ. Pollut., 202, 217-219, 2015.

Zhang, Z., Gao, J., Engling, G., Tao, J., Chai, F., Zhang, L., Zhang, R., Sang, X., Chan, C.-y., and Lin, Z.: Characteristics and applications of size-segregated biomass burning tracers in China's Pearl River Delta region, Atmos. Environ., 102, 290-301, 2015.

Zhao, L., Leng, Y., Ren, H., and Li, H.: Life cycle assessment for large-scale centralized straw gas supply project, J. Anhui Agri. Sci., 38, 19462-19464, 2010.

Zhao, S., Tie, X., Cao, J., and Zhang, Q.: Impacts of mountains on black carbon aerosol under different synoptic meteorology conditions in the Guanzhong region, China, Atmos. Res., 164, 286296, 2015.

Zhu, J., Wang, T., Deng, J., Jiang, A., and Liu, D.: An emission inventory of air pollutants from crop residue burning in Yangtze River Delta Region and its application in simulation of a heavy haze weather process, Acta Scientiae Circumstantiae, 32, 30453055, 2012. 